\title{
Heat Shock Cognate Protein 70 Regulates Gephyrin Clustering
}

\author{
Patricia Machado, ${ }^{1,2,3}$ Philippe Rostaing, ${ }^{1,2,3}$ Jean-Marie Guigonis, ${ }^{4}$ Marianne Renner, ${ }^{1,2,3}$ Andréa Dumoulin, ${ }^{1,2,3}$ \\ Michel Samson, ${ }^{4}$ Christian Vannier, ${ }^{1,2,3}$ and Antoine Triller ${ }^{1,2,3}$ \\ ${ }^{1}$ Institut de Biologie de l'Ecole Normale Supérieure, ${ }^{2}$ Institut National de la Santé et de la Recherche Médicale U1024, ${ }^{3}$ Centre National de la Recherche \\ Scientifique Unité Mixte de Recherche 8197, 75005 Paris, France, and ${ }^{4}$ Institut Fédératif de Recherche 50 - Université de Nice-Sophia Antipolis, Faculté de \\ Médecine Pasteur, 06107 Nice, France
}

Formation and stabilization of postsynaptic glycine receptor (GlyR) clusters result from their association with the polymerized scaffold protein gephyrin. At the cell surface, lateral diffusion and local trapping of GlyR by synaptic gephyrin clusters is one of the main factors controlling their number. However, the mechanisms regulating gephyrin/GlyR cluster sizes are not fully understood. To identify molecular binding partners able to control gephyrin cluster stability, we performed pull-down assays with full-length or truncated gephyrin forms incubated in a rat spinal cord extract, combined with mass spectrometric analysis. We found that heat shock cognate protein 70 (Hsc70), a constitutive member of the heat shock protein 70 (Hsp70) family, selectively binds to the gephyrin G-domain. Immunoelectron microscopy of mouse spinal cord sections showed that Hsc70 could be colocalized with gephyrin at inhibitory synapses. Furthermore, ternary Hsc70-gephyrin-GlyR coclusters were formed following transfection of COS-7 cells. Upon overexpression of Hsc70 in mouse spinal cord neurons, synaptic accumulation of gephyrin was significantly decreased, but GlyR amounts were unaffected. In the same way, Hsc70 inhibition increased gephyrin accumulation at inhibitory synapses without modifying GlyR clustering. Single particle tracking experiments revealed that the increase of gephyrin molecules reduced GlyR diffusion rates without altering GlyR residency at synapses. Our findings demonstrate that Hsc70 regulates gephyrin polymerization independently of its interaction with GlyR. Therefore, gephyrin polymerization and synaptic clustering of GlyR are uncoupled events.

\section{Introduction}

Fast neurotransmission at central synapses depends on the enrichment of ionotropic receptors in the postsynaptic membrane, in front of the corresponding neurotransmitter release sites. Gephyrin is a scaffold protein implicated in the formation and stabilization of inhibitory postsynaptic $\mathrm{GABA}_{\mathrm{A}}$ - and glycine receptors (GABA $\mathrm{A}$ and GlyR) clusters (Specht and Triller, 2008). Lateral diffusion and local trapping of receptors have emerged as two of the main factors regulating their number, modulating in turn the synaptic strength (Triller and Choquet, 2008). Thus, GlyR number at synapses is controlled by the gephyrin receptor binding capacity and self-oligomerization at the postsynaptic differentiation (Calamai et al., 2009).

Gephyrin is a tripartite polypeptide (Fritschy et al., 2008, see their see references). The tertiary and quaternary structures of the $\mathrm{N}$ - and C-terminal domains (G- and E-domains, respectively) (Liu et al., 2000; Xiang et al., 2001; Kim et al., 2006) show that

\footnotetext{
Received May 18, 2010; revised July 27, 2010; accepted Aug. 2, 2010.

We are very grateful for support from the Fondation pour la Recherche Médicale and the Institut de Recherche sur la Moelle epinière et l'Encéphale. We thank C. Specht and L. Hennekinne for valuable discussions, S. Marty for valuable help with the generation of the knock-in mouse, and A. Ayadi at the Institut Clinique de la Souris (Strasbourg, France) for the establishment of the knock-in mouse strain.

Correspondence should be addressed to Antoine Triller, INSERM U1024 - Laboratoire de Biologie Cellulaire de la Synapse, Institut de Biologie de l'Ecole Normale Supérieure, 46, rue d'Ulm, 75005 Paris, France. E-mail: triller@ biologie.ens.fr.

DOI:10.1523/JNEUROSCI.2533-10.2011

Copyright $\odot 2011$ the authors $\quad 0270-6474 / 11 / 310003-12 \$ 15.00 / 0$
}

gephyrin has two distinct oligomerization potentials. Isolated Gand E-domains form stable trimers and dimers, respectively, and the full-length gephyrin forms a stable trimer (Schrader et al., 2004; Sola et al., 2004). However, trimeric, hexameric and higher order structures have been observed depending on whether the E-domain is in a dimeric or metastable monomeric conformation (Sola et al., 2004; Bedet et al., 2006; Saiyed et al., 2007). It is thought that these oligomerization properties underpin the organization of gephyrin into a two-dimensional hexagonal lattice (Prior et al., 1992; Xiang et al., 2001). Despite the demonstration that gephyrin splice variants with altered oligomerization properties can participate in the lattice remodeling (Bedet et al., 2006), the mechanisms responsible for gephyrin cluster assembly and disassembly, which must be regulated at the synapse, are still unknown.

In addition to interacting with itself, gephyrin also interacts with several partners, suggesting a complex regulation of both gephyrin oligomerization and receptor to scaffold interactions. Known molecular partners include $\mathrm{GABA}_{\mathrm{A}} \mathrm{R} \alpha_{2^{-}}$and GlyR $\beta$-subunits, polymerized tubulin (Kirsch et al., 1991), profilin (Mammoto et al., 1998), RAFT-1 (Sabatini et al., 1999), collybistin (Kins et al., 2000), dynein light chains 1 and 2 (Fuhrmann et al., 2002), Mena/VASP (Giesemann et al., 2003), the chaperone protein Pin1 (Zita et al., 2007) and kinesin family motor protein 5, KIF5 (Maas et al., 2009). A current view is that some of these proteins are implicated in transport and/or clustering of gephyrin (Fritschy et al., 2008, see their see references). 
In this study, a proteomic screen using pull-down assays and mass spectrometric analysis led to the identification of a new synaptic binding partner of gephyrin, heat shock cognate protein 70 (Hsc70). In spinal cord sections, Hsc70 was observed at synaptic sites by immunoelectron microscopy. Furthermore, functional studies revealed that Hsc70 affects gephyrin clustering, but did not affect GlyR amount at synapses. Altogether, our results indicate that Hsc70 controls gephyrin polymerization independently of GlyR trapping at synapses.

\section{Materials and Methods}

Purification of the His-tagged gephyrin. Purification of the recombinant full-length $[\mathrm{Ge}(2)]$ and truncated $[\mathrm{Ge}(2), \mathrm{CE}, \mathrm{E}]$ gephyrins was performed as described previously (Bedet et al., 2006) under native conditions at $4^{\circ} \mathrm{C}$. Routinely, full-length and truncated gephyrins were expressed in transformed Escherichia coli BL21 (DE3) (Novagen) induced with $0.5-1 \mathrm{~mm}$ isopropyl- $\beta$-thiogalactoside for $3 \mathrm{~h}$ at $37^{\circ} \mathrm{C}$. Purification was performed using the soluble fraction of cell lysates by nickel-iminodiacetic acid $\left(\mathrm{Ni}^{2+}\right.$-IDA) affinity chromatography according to the manufacturer's instructions (Macherey-Nagel). Purified proteins were analyzed by $12 \%$ SDS-PAGE.

Pull-down assays. Spinal cord from adult male rats was excised, frozen in liquid nitrogen, and homogenized in extraction buffer (containing, in mм: 25 Tris- $\mathrm{HCl}, \mathrm{pH} 7.5,150 \mathrm{NaCl}, 10 \%$ (w/v) sucrose, $12.5 \beta$-MSH, protease inhibitors) (Roche Applied Science) and subsequently lysed with $1 \%(\mathrm{w} / \mathrm{v})$ Triton $\mathrm{X}-100$. The soluble extract was obtained by centrifugation ( $45 \mathrm{~min} ; 100000 \mathrm{~g} ; 4^{\circ} \mathrm{C}$ ) and was precleared at $4^{\circ} \mathrm{C}$ for $2 \mathrm{~h}$ by Ni-NTA agarose (Qiagen). Gephyrin protein-coated preequilibrated nickel-iminodiacetic acid ( $\left.\mathrm{Ni}^{2+} \mathrm{IDA}\right)$ silica-based resin ( $16 \mu \mathrm{M}$ final concentration) was incubated with precleared cell lysate $(7 \mathrm{mg} / \mathrm{ml}$ protein) at $4^{\circ} \mathrm{C}$ overnight. Then, the gephyrin resin was washed five times (once with $500 \mathrm{~mm} \mathrm{NaCl}$ ), and proteins were eluted with $4 \mathrm{~m}$ urea in $25 \mathrm{~mm}$ Tris$\mathrm{HCl}, \mathrm{pH} 7.5$, from the $\mathrm{Ni}^{2+}$-affinity column. Eluted protein was concentrated using the Pierce SDS-PAGE Sample Prep Kit, and directly diluted with tricine sample buffer without $\beta$-MSH to a total of $200 \mu \mathrm{l}$ and subjected to SDS-PAGE on a $1 \mathrm{~mm}$-thick gel using a 10\%T, 3\%C discontinuous tricine system (Schägger and von Jagow, 1987). Immediately after electrophoresis, the gel was fixed and processed for silver staining (Blum et al., 1987) before mass spectrometry analysis. Affinity enrichment of proteins able to associate with gephyrin and its fragments was performed in duplicate.

Similar analytical pull-down assays were performed using immobilized purified G(2) and E-protein and purified Hsc70 (SPP-751, Stressgen). Purified gephyrin (16 $\mu \mathrm{M})$ was prewashed with $5 \mathrm{~mm}$ ATP, $5 \mathrm{~mm}$ $\mathrm{MgCl}_{2}$ before incubation with $\mathrm{Hsc70}(260 \mathrm{nM})$ preincubated with $\operatorname{ATP} \gamma \mathrm{S}$, ADP and ATP $(0,1,5$ and $25 \mathrm{~mm})$ and $10 \mathrm{~mm}$ clofibric acid (CA) (Sigma-Aldrich). Gephyrin-coated $\mathrm{Ni}^{2+}$-IDA resin was sedimented after washing and bound material was processed for Western blot analysis using goat anti-Hsc70 antibody (SC-1059, Santa Cruz Biotechnology). Signal intensities of bands were calculated using NIH ImageJ software. Signals were normalized to that of ADP. Data were obtained from four independent experiments.

Protein identification by mass spectrometry. In-gel tryptic digestion and processing of samples was performed as described previously (Cayatte et al., 2006). Selected protein bands were manually excised from the gel and destained with $50 \%$ acetonitrile in $25 \mathrm{~mm}$ ammonium bicarbonate. Gel pieces were then crushed in Eppendorf tubes, dehydrated with acetonitrile for $5 \mathrm{~min}$, and dried under vacuum. After rehydration with up to $15-50 \mu \mathrm{l}$ of $25 \mathrm{~mm}$ ammonium bicarbonate, $10 \%$ acetonitrile containing $5 \mathrm{ng} / \mu \mathrm{l}$ trypsin (V5111, Promega) samples were incubated at $37^{\circ} \mathrm{C}$ for $16 \mathrm{~h}$. The incubation volume was adjusted to $100 \mu \mathrm{l}$ with ultra-pure water and acidified with formic acid at 5\% (v/v) (final concentration). Afterward, tryptic peptides were extracted by 15 min incubations, consecutively in 5\% formic acid, 50\% acetonitrile, and $80 \%$ acetonitrile. Sonications ( $7 \mathrm{~min}, 400 \mathrm{~W}$, Deltasonic) were also performed during incubations to facilitate peptide extraction. Extracts were pooled before being evaporated under vacuum, and dry peptide samples were redissolved in 5\% formic acid, $20 \%$ methanol.
All samples were analyzed as previously described (Cayatte et al., 2006). Briefly, mass spectra were recorded with a MALDI-TOF spectrometer (Voyager DE-PRO, PerSeptive Biosystems) set in positive reflectron mode. Peptide masses were compared with the theoretical masses derived from the sequences contained in Swiss-Prot/TrEMBL databases or deduced from the nonredundant National Center for Biotechnology Information (nrNCBI) database. No restrictions were placed on species of origin, $\mathrm{pI}$, or protein mass range. To confirm peptide mass fingerprinting results, some samples were analyzed by nano-ESI-MS/MS (static infusion) on an LCQDECA XP-PLUS mass spectrometer (ThermoQuest). Nanoelectrospray capillaries (ES 381, Proxeon Biosystems) were used as emitter. Acquired MS/MS spectra were interpreted using Bioworks (version 3.1 ThermoQuest) and MASCOT (on line) or DeNovoX (Version 1.0, ThermoQuest) softwares and were used for de novo sequencing analyses performed with DeNovoX software.

Constructs and expression plasmids. The Venus-tagged version of Hsc70 was obtained by fusing rat Hsc70 to the Venus-yellow fluorescent protein (YFP) (Nagai et al., 2002) C terminus via a AlaThr spacer sequence. The rat Hsc70 sequence was amplified by PCR from plasmid LK333 kindly donated by Dr. O. Bensaude (ENS, Paris, France) with forward 5'-AAGCTGTACAAGGCCACCATGTCCAAGGGACCTGCGGTTGGC-3' and reverse 5' -CCCCGCGGCCGCTTAATCGACCTCTTCAATGGTGG-3' primers generating BsrGI and NotI sites at the $5^{\prime}$ and $3^{\prime}$ ends, respectively. The PCR fragments were subcloned into the pVenus::gephyrin (Hanus et al., 2006) after removing the gephyrin fragment at the BsrGI/NotI sites.

The T7-mRFP construct was obtained with two rounds of PCR amplification. The monomeric red fluorescent protein (mRFP)-encoding sequence was first amplified (5'-GGCTAGCATGACTGGTGGACAGCAAATGGGTGGCGGCTCCATGGCCTCCTCCGAGGAC-3' and 5' -TACAGGTTTTCGGTGGTGCCGATGGCGGCGCCGGTGGAGTGGC-3') from the plasmid pRSETB-mRFP1 provided by Prof. R. Tsien (University of California) (Campbell et al., 2002). The PCR fragment was subsequently amplified (5'-GCTTGTCGACGGCGGCATGGCTAGCATGACTGGCGGCCAGCAAATGGCTAGCATGACTGGTGG-3' and 5'-GCTTACTAGTGCCGATATCGGCGGCGCCCTGAAAATACAGGTTTTCGGTGGTGC-3') to be subcloned into pSL1190 vector using the SalI and SpeI restriction sites. The T7-mRFP was amplified (5'-GATTGTCGACGGCGGCATGGCTAG-3' and 5'-GAACGCGGCCGCTTCTTAGGCGGCGCCCTGAAAATACAG-3') to be inserted in pEGFP-N1 expression vector (Clontech) using SalII and NotI sites.

To construct C2mRFP.Ge(2), the T7-mRFP sequence was fused to gephyrin (2) (clone 1, Prior et al., 1992) into the cassette C2 (exon 3) between amino acids N29 and L30. The first 87 bp of gephyrin was amplified ( $5^{\prime}-$ TAGCAAGCTTGATTCACTTCTCCCGGCTCCTGTC-3' and 5'-GCTTCTCGAGATTCCTGAAGCAGCTATCAC-3') and subcloned in pSL1190 vector using restriction sites HindIII and XhoI. The other part of gephyrin was amplified by PCR until restriction site EcoRI ( 5 ' -GCTTGCTAGCCTTGCAGAAGACCGCAGTG-3' and 5'-GCTTCTCGAGTCACACCAGAATTCGCACTTCAAG-3') and subcloned in the same PSLL1190 vector by using NheI and EcoRI sites. T7-mRFP fragment was cut from pSL1190 vector using SalI/SpeI sites and inserted between the two fragments of gephyrin using Xhol/NheI sites. A HindIII-EcoRI fragment was generated and inserted downstream to the last $874 \mathrm{bp}$ of gephyrin in a pCMV vector to generate the full-length fusion molecule. The primary structure of the various constructs was checked by DNA sequencing.

The construction of GlyR myc- $\alpha 1 \beta$ gb subunit bearing the 18 -residue gephyrin-binding motif of the $\beta$-subunit has been described previously (Meyer et al., 1995; Meier et al., 2000a).

A gephyrin-mRFP knock-in mouse (C57BL/6J) was generated by targeted insertion of the T7-mRFP sequence into exon 3 after the codon of N29. For this, the plasmid encoding the chimera C2mRFP.Ge(2) was used to allow homologous recombination in regions flanking exon 3. Only homozygous male animals were used in this study.

Cell culture, transfection and pharmacological treatment. Plating and transfection of African green monkey kidney (COS-7) cells were performed as described before (Hanus et al., 2004). Primary cultures of spinal cord neurons were prepared from embryonic gephyrin-mRFP knock-in or wild-type mice (day 13 of gestation) as described previously (Rosenberg et al., 2001; Bedet et al., 2006). Neurons were transfected $8 \mathrm{~d}$ 
in vitro (DIV) after plating using Lipofectamine2000 (Invitrogen) according to the protocol of the manufacturer. Transient protein expression was allowed to proceed for up to $48 \mathrm{~h}$. When indicated, spinal cord neurons (8-10 DIV) were incubated for $48 \mathrm{~h}$ with $2 \mathrm{~mm}$ CA [from a $1 \mathrm{M}$ ethanol stock (Sigma-Aldrich)].

Coimmunoprecipitation. Coimmunoprecipitation experiments were performed in two independent experiments. COS-7 cells were transiently transfected with the appropriate vectors and resuspended in $25 \mathrm{~mm}$ Tris$\mathrm{HCl}, \mathrm{pH} 7.5,150 \mathrm{~mm} \mathrm{NaCl}, 10 \%$ (w/v) sucrose, $12.5 \mathrm{~mm} \beta$-MSH, protease inhibitors, $0.1 \%(\mathrm{w} / \mathrm{v})$ Tween 20 . The cleared extract was incubated with $5 \mu \mathrm{g}$ of the mouse anti-T7 antibody (Novagen), followed by the addition of $25 \mu \mathrm{l}$ of protein G-Sepharose beads (Sigma-Aldrich). Beads were sedimented after washing and processed for SDS-PAGE. The goat anti-Hsc70 antibody and rabbit anti-T7 antibody (GeneTex, Inc.) were used for Western blot detection.

Immunoprecipitation of endogenous gephyrin from spinal cord was performed under buffer conditions identical to those used for the pulldown experiment from rat spinal cord (see above). Spinal cords from homozygous gephyrin-mRFP knock-in and wild-type mice were homogenized in $25 \mathrm{~mm}$ Tris- $\mathrm{HCl}$, pH 7.5, $150 \mathrm{~mm} \mathrm{NaCl}, 10 \%$ (w/v) sucrose, 12.5 mм $\beta$-MSH, protease inhibitors, $10 \mathrm{~mm} \mathrm{NaF}, 2 \mathrm{~mm} \mathrm{Na}_{3} \mathrm{VO}_{4} 5 \mathrm{~mm}$ $\mathrm{Na}_{4} \mathrm{P}_{2} \mathrm{O}_{7}$ and lysed with $1 \%(\mathrm{w} / \mathrm{v})$ Triton X-100. After centrifugation (45 min; $100000 \mathrm{~g} ; 4^{\circ} \mathrm{C}$ ), the soluble extract was incubated with T7•Tag Antibody Agarose (Novagen). Precipitated complexes were subsequently detected by Western blotting using polyclonal anti-gephyrin antibody (Santa Cruz Biotechnology), goat anti-Hsc70 antibody and rabbit antiPin 1 antibody (obtained from O. Bensaude) (Lavoie et al., 2001).

Electron microscopy and immunocytochemistry. Adult homozygous knock-in mice were deeply anesthetized with pentobarbital $(60 \mathrm{mg} / \mathrm{kg}$ body mass) and intracardially perfused with $4 \%(\mathrm{w} / \mathrm{v})$ paraformaldehyde (PFA) $-0.1 \%(\mathrm{w} / \mathrm{v})$ glutaraldehyde (Polysciences). After dissection, the cervical spinal cord was postfixed at $4^{\circ} \mathrm{C}$ overnight in $4 \%$ PFA.

The entire procedure for gold staining and silver-intensification was performed essentially as described previously (Fuhrmann et al., 2002). Hsc70 was immunostained on vibratome sections $(200 \mu \mathrm{m})$ of cervical spinal cord using rat anti-Hsc70 antibody (SPA-815, Stressgen). For gephyrin labeling, sections were gradually dehydrated in ethanol and embedded in Lowicryl HM20 (Polysciences) in AFS REICHERT (Leica Microsystems) after a progressive lowering of temperature. In the case of double-labeling immunochemistry of Hsc70 and gephyrin, some gold-toned sections described above were used and not osmificated. After polymerization under UV light at $-45^{\circ} \mathrm{C}$ for $48 \mathrm{~h}$, pale yellow sections collected on nickel grids coated with formvar, were incubated for $30 \mathrm{~min}$ in goat gold-conjugate blocking solution (Aurion). Sections were subsequently incubated overnight at $4^{\circ} \mathrm{C}$ with rabbit anti-T7 antibody (1/5000). After extensive washes, the sections were incubated for $1 \mathrm{~h}$ at room temperature in $10 \mathrm{~nm}$ goldconjugated secondary antibodies against rabbit IgG (1/50, British Biocell International). They were then washed and fixed $5 \mathrm{~min}$ in $2 \%$ glutaraldehyde. Sections were counterstained with uranyl acetate and lead citrate for inspection with a Philips Tecnai 12 electron microscope (FEI, Eindhoven, The Netherlands).

Immunofluorescence labeling of cultured cells. Immunofluorescence labeling was performed essentially as described previously (Rosenberg et al., 2001) on cells that were fixed in $4 \%$ (w/v) paraformaldehyde. GlyR was labeled with rabbit anti- $\alpha 1$-subunit antibody $(1 / 250)$. After permeabilization, neurons were incubated with monoclonal anti-MAP2ab antibody (1/1000, Millipore Bioscience Research Reagents), or with mouse anti-gephyrin antibody mAb 7a (1/800, Synaptic Systems). For Homer staining, permeabilized neurons were incubated with rabbit anti-Homer antibody (1/250, Synaptic Systems). After washes, cells were incubated for $45 \mathrm{~min}$ at $37^{\circ} \mathrm{C}$ with Alexa 488 -conjugated goat anti-rabbit $(1 / 800$, Invitrogen) or Cy3-conjugated goat anti-rabbit (1/1000, Jackson Laboratories) and Alexa 647-conjugated donkey anti-mouse antibody (1/500, Invitrogen). For c-myc-tagged GlyR labeling in COS-7 cells, fixed and permeabilized cells were incubated with monoclonal anti-c-myc antibody $(0.5 \mu \mathrm{g} / \mathrm{ml}, 9 \mathrm{E} 10$, Roche Applied Science), followed by Alexa 647conjugated donkey anti-mouse antibody (1/800, Invitrogen).

Fluorescence image acquisition and quantification analysis. Fluorescence pictures were usually acquired with a confocal microscope (Leica
DM5000B; spinning disk CSU10, Yokogawa; Photometrics 63× immersion objective) equipped with a CCD camera (Coolsnap, Princeton Instruments). Twelve-bit images were acquired using MetaView software (Meta Imaging, Molecular Devices). For each culture, Homer, GlyR, gephyrin or MAP2ab images were acquired with the same exposure time between control and treated coverslips. Quantification was performed using MetaMorph software (Meta Imaging, Molecular Devices). Binary masks corresponding to Homer, GlyR or gephyrin clusters were created by thresholding images segmented with multidimensional image analysis (MIA) (Racine et al., 2007). For each neuron the Homer, GlyR and gephyrin-associated fluorescence intensities were measured using the corresponding mask. Neurites were randomly chosen with the MAP2ab channel, and GlyR $\alpha 1$ and gephyrin clusters comprising at least two pixels and colocalized on at least one pixel were considered. Data are expressed as mean \pm SEM from three independent experiments. For ratiometric analysis, gephyrin/GlyR $\alpha 1$ integrated fluorescence intensity was performed cluster by cluster using Matlab software (MathWorks), and was represented and pseudocolored with NIH ImageJ software.

Images of COS-7 cells transfected with pC-myc- $\alpha 1 \beta \mathrm{gb}$ were acquired using a Leica TCS SP2 upright epifluorescence microscope $(63 \times / 1.32$ oil-immersion objective). Wavelength ranges chosen for acquisition were 540-555 (Venus or EGFP), 568-621 (mRFP) and 650-728 (Alexa 647 dye).

Live cell staining of glycine receptor for single-particle imaging. Living neurons were incubated for $3 \mathrm{~min}$ at $37^{\circ} \mathrm{C}$ with the monoclonal antibody against the GlyR $\alpha 1$-subunit extracellular epitope (mAb 2b) (Ehrensperger et al., 2007). Biotinylated anti-mouse Fab fragment (Jackson Laboratories) was used as secondary antibody at a 1:1000 dilution. Streptavidin-coated QDs (Invitrogen) emitting at $605 \mathrm{~nm}$ were used $(0.2-0.3 \mathrm{nM})$. Cells were then washed and imaged in the presence of CA or ethanol. All washes, incubation steps, and cell imaging were performed in recording medium.

Single-particle tracking and analysis. Real-time fluorescence images were obtained with an integration time of $50 \mathrm{~ms}$ with a CCD camera (Micromax 512EBFT, Roper Scientific), with 500 consecutive frames acquired with MetaView (Molecular Devices). Cells were imaged within 30 min following primary antibody incubation. For each single-particle tracking experiment, QD dynamics were measured on 30 movies from three separate coverslips per condition. Data were obtained from three independent cultures.

Single-molecule tracking, analysis, and dwell time measurements were performed as described previously (Charrier et al., 2006; Ehrensperger et al., 2007). Synapse dwell time was calculated as the mean duration of each trajectory episode in a synaptic region excluding trajectories that remain in the gephyrin clusters during the recording time of $25 \mathrm{~s}$.

Gephyrin detection in spinal cord neurons and TEV protease cleavage. For the detection of gephyrin in wild-type and gephyrin-mRFP knock-in spinal cord culture, crude extracts were separated by SDS-PAGE. Polyclonal anti-gephyrin antibody (Santa Cruz Biotechnology) obtained against the C-terminal 300-amino acid sequence, and the monoclonal anti-T7 antibody (Novagen) were used for Western blot detection.

Cultured spinal cord neurons from derived gephyrin-mRFP knock-in mice were resuspended in $25 \mathrm{~mm}$ Tris- $\mathrm{HCl}$, pH 7.5, $150 \mathrm{~mm} \mathrm{NaCl}, 10 \%$ $(\mathrm{w} / \mathrm{v})$ sucrose, $12.5 \mathrm{~mm} \beta-\mathrm{MSH}$, protease inhibitors, 3\% (w/v) Triton $\mathrm{X}-100$. The cleared extract was incubated for $2 \mathrm{~h}$ with mouse T7 $\bullet$ Tag antibody agarose (Novagen). After washing, beads were processed for TEV protease cleavage overnight, according to the manufacturer's instructions (Invitrogen). Beads were analyzed by SDS-PAGE and Western blotting using polyclonal anti-gephyrin antibody and with monoclonal anti-T7 antibody.

Fluorescence immunohistochemistry. This method was applied to the spinal cord of the homozygous gephyrin-mRFP knock-in mice. Adult male animals were subjected to the same protocol as for electron microscopy with the exception that no glutaraldehyde was added to the perfusion solution. For immunofluorescence analysis, spinal cord was cryoprotected overnight at $4^{\circ} \mathrm{C}$ in $\mathrm{PBS} / 20 \%$ sucrose. Cryotome sections $(40 \mu \mathrm{m})$ were blocked with $0.1 \%(\mathrm{w} / \mathrm{v})$ Triton X-100/0.25\% (w/v) gelatin/PBS incubated overnight with the monoclonal anti-gephyrin antibody (mAb 7a, 1/800, Synaptic Systems), rabbit anti-VIAAT (vesicular inhibitory amino acid transporter) antibody (1/1500) provided by Bruno 
Gasnier (l'Institut de Biologie PhysicoChimique, Paris, France), rabbit anti-T7 antibody (1/1000) or rabbit anti-Homer antibody ( $1 / 250$, Synaptic Systems) in $0.1 \%$ (w/v) Triton $\mathrm{X}-100,0.12 \%(\mathrm{w} / \mathrm{v})$ gelatin in PBS. After washes, slices were incubated for $3 \mathrm{~h}$ with Alexa 488-conjugated goat anti-mouse or Alexa 488conjugated goat anti-rabbit antibodies $(1 / 800$, Invitrogen).

Immunofluorescence labeling of cultured spinal cord neurons. Cultured spinal cord neurons from gephyrin-mRFP knock-in mouse were fixed in $4 \%(\mathrm{w} / \mathrm{v})$ paraformaldehyde and blocked with $0.25 \%(\mathrm{w} / \mathrm{v})$ gelatin/PBS. After permeabilization, neurons were incubated with monoclonal anti-gephyrin antibody (mAb 7a, 1/800), rabbit anti-VIAAT antibody (1/1500), rabbit antiT7 antibody (1/1000) or mouse anti-GlyR $\alpha 1$ subunit antibody (mAb 2b, 1/100, Synaptic Systems). After washes, Alexa 488-conjugated goat anti-rabbit and Alexa 488-conjugated goat anti-mouse antibodies $(1 / 800)$ were incubated for $45 \mathrm{~min}$.

\section{Results}

Gephyrin partners were previously discovered by yeast two-hybrid system ( $\mathrm{Dlcl} / 2$, Collybistin, GABARAP, RAFT1) or by pulldown assay with gephyrin as a prey from a cellular extract (Profilin, Pin1). In other cases, biochemical studies using recombinant proteins as baits and preys (Mena/ VASP) or coimmunoprecipitation (KIF5) were performed to confirm potential interactions (Fritschy et al., 2008, see their see references). To discover new gephyrin partner, a new screen was performed. Here, we performed affinity pull-down assay using recombinant gephyrin as a bait incubated in a tissue lysate. This approach differs from previous ones since a tagged gephyrin is used as a specific affinity matrix therefore allowing the capture of strong interacting or slowly dissociating partners from a "native" protein environment.

\section{The G-domain of gephyrin interacts with the heat shock protein Hsc70}

We performed pull-down experiments with purified recombinant full-length or truncated gephyrin forms expressed in $E$. coli (Fig. 1A,B). Gephyrin is composed of three main domains: the $\mathrm{N}$-terminal G-domain and the C-terminal E-domain of gephyrin are linked by the central C-domain (previously called L) (Fritschy et al., 2008). The recombinant full-length molecule GCE, referred to as $\mathrm{Ge}(2)$ and the fragments $\mathrm{G}(2)$ (aa 1-184), E (aa 308-736), and CE (aa 171-736) have been described previously (Bedet et al., 2006) and were used as bait in the present work (Fig. 1A). The pull-down conditions were designed so that only cytoplasmic proteins exhibiting a high affinity constant or low dissociation kinetics or both would be recovered in complexes with the gephyrin forms tested. The various gephyrin constructs were incubated separately at the same final concentration $(16 \mu \mathrm{M})$ with a precleared soluble extract from adult rat spinal cord, as described in Materials and Methods. After immobilized metal-affinity chromatography on a $\mathrm{Ni}^{2+}$-IDA resin, the enriched prey proteins
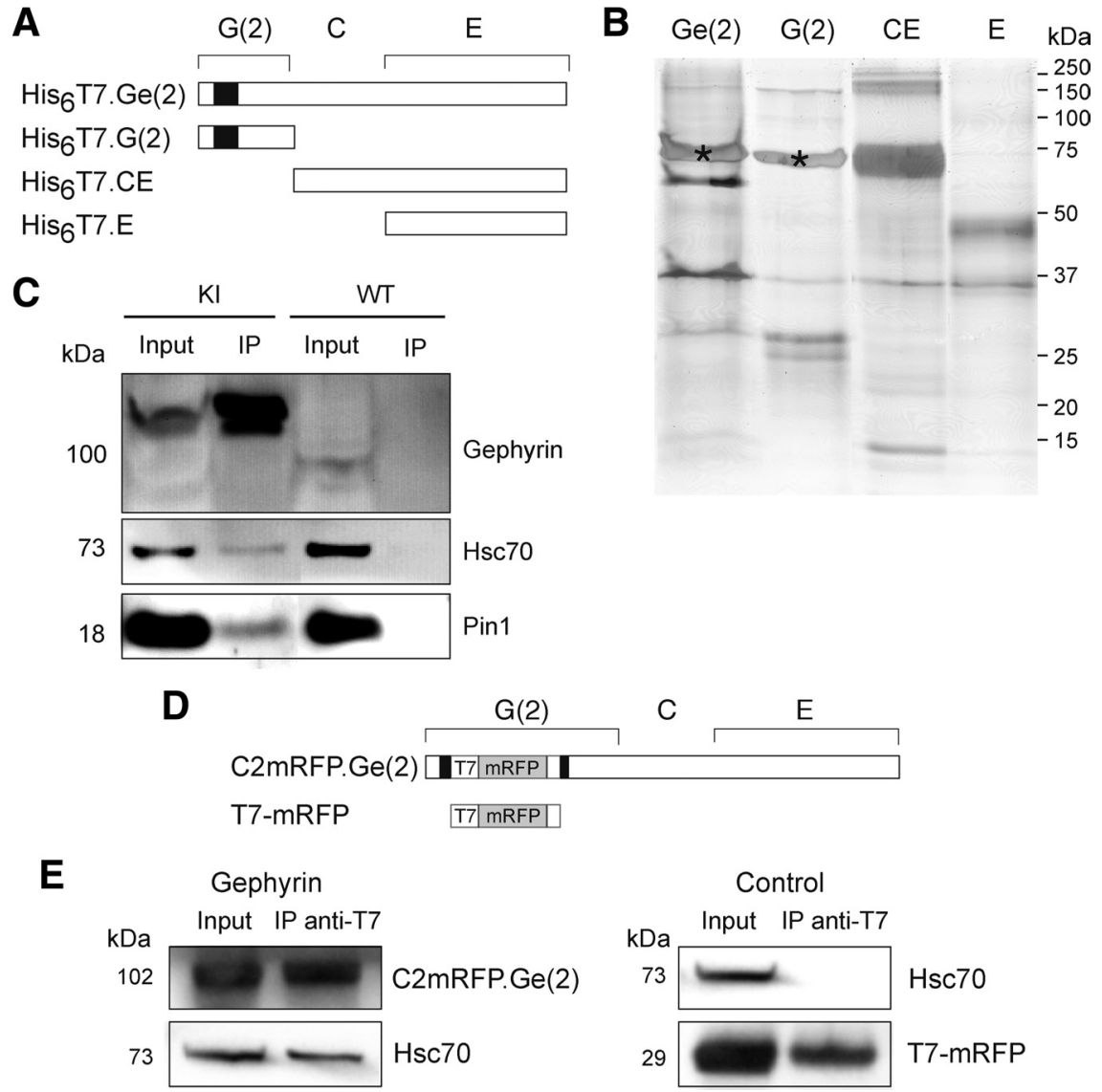

Figure 1. Gephyrin and Hsc70 interact in vitro and form complexes in COS-7 cells. $\boldsymbol{A}$, Rod structure of tagged-recombinant

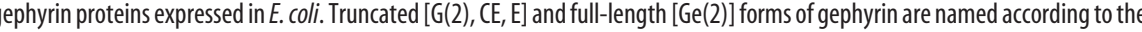
omain structure of the full-length molecule [variant $(2,6)$ ] (Prior et al., 1992). Cassette $(2$ is indicated by the black box. $\boldsymbol{B}$ assay. Full-length $\mathrm{Ge}(2)$ and truncated proteins were incubated with rat spinal cord extract as described in Materials and $\mathrm{kDa}\left({ }^{*}\right)$ in lanes $\mathrm{Ge}(2)$ and $\mathrm{G}(2)$ was identified by mass spectrometry analysis as containing $\mathrm{Hsc} 70$ (two independent experiments; see supplemental Fig. 1, supplemental Table 1, available at www.jneurosci.org as supplemental material). C, Coimmunoprecipitation of gephyrin and Hsc70 from spinal cord extract from homozygous gephyrin-mRFP knock-in mice. Using beads conjugated with anti-T7 antibody, gephyrin complexed to $\mathrm{Hsc70}$ and Pin1 was precipitated. Note that none of these proteins was precipitated that contains mRFP and T7 tags in the middle of the 22 cassette (black box), of its G-domain, and the control construct (T7-mRFP) Endogenous Hsc70 coimmunoprecipitates with transfected C2mRFP.Ge(2). COS-7 cells were transfected with either C2mRFP.Ge(2) (left) or T7-mRFP (control, right) and subjected to coimmunoprecipitation with anti-T7 antibodies. Hsc70 was detected by Western blot analysis when recombinant gephyrin was expressed (two independent experiments).

were separated by one-dimensional SDS-PAGE, and digests of the indicated bands (Fig. $1 B$ ) were subsequently analyzed by LCESI-MS/MS mass spectrometry. With this protocol we identified, in four comparative assays, heat shock cognate 70 (Hsc70, heat shock $70 \mathrm{kDa}$ protein 8 ), a member of heat shock protein 70 (Hsp70) family, which showed a clear differential behavior (supplemental Fig. 1, supplemental Table 1, available at www. jneurosci.org as supplemental material). Remarkably, only Hsc70 was captured by both the full-length $\mathrm{Ge}(2)$ protein and the G-domain, but not by the CE and E proteins. No other member of the Hsp70 protein family, including inducible molecules (supplemental Fig. 1, available at www.jneurosci.org as supplemental material), as well as other heat shock proteins, could be detected (data not shown). Because of this selectivity, we could exclude that Hsc70 was captured either by nonspecific adsorption on the affinity matrix or as a result of binding to an abnormally folded recombinant bait protein. Because of the propensity of the purified G- and E-domains to trimerize and dimerize into stable 

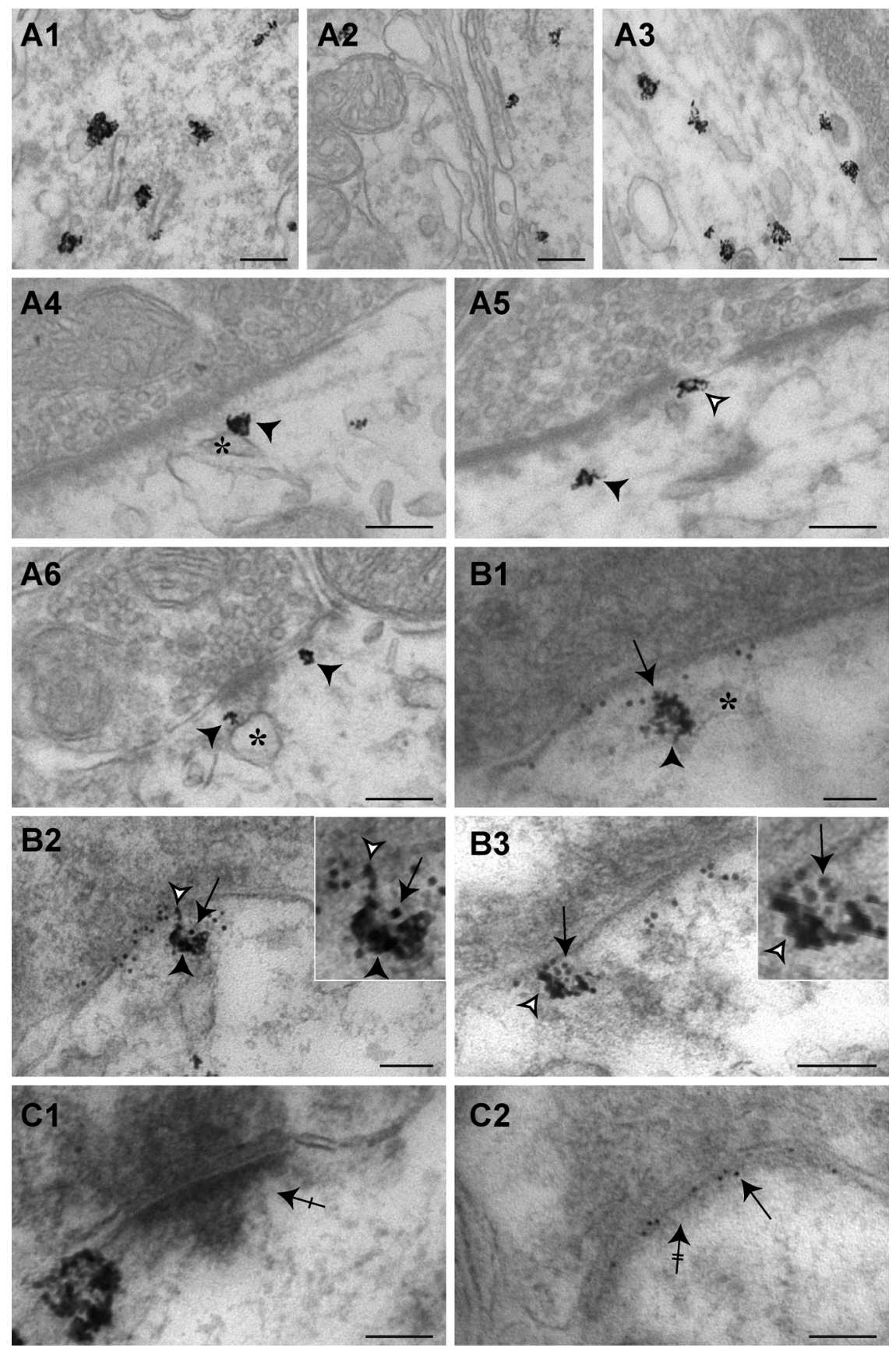

Figure 2. Gephyrin and Hsc70 colocalize at inhibitory synapses of spinal cord neurons from homozygous gephyrin-mRFP knock-in mice. A1-A6, Electron microscopy of dendritic and subsynaptic labeling of Hsc70. Hsc70 detected by intensified goldtoned nanogold labeling was associated with rough endoplasmic reticulum (A1), Golgi apparatus (A2), and microtubules (A3). The deposits of immunoenzymatic reaction product were observed at the periphery of dendrites, juxtaposed with synapses (arrowheads). Note the presence of gold-labeled Hsc70 on cisternae in the vicinity of the PSD (A4, black arrowheads and asterisks, respectively) and on the edge of the PSD ( $\boldsymbol{A} 5$, white arrowhead). Inhibitory presynaptic boutons were identified by the presence of pleomorphic vesicles. Hsc70 was also observed in excitatory synapses (A6, arrowheads). B1-B3, Subcellular colocalization of gephyrin- and Hsc70-IR labeled with immunogold and intensified gold-toned nanogold particles, respectively. Hsc70immunoreactivity (arrowheads) was associated with gephyrin (arrows) close to the postsynaptic membrane (B1 and $\boldsymbol{B 2}$, black arrowheads) or in the inhibitory PSD ( $\boldsymbol{B}$ and $\boldsymbol{B} \mathbf{3}$, white arrowheads). Note that $\mathrm{Hsc70}$ was localized at the edge of the differentiation. C, Control of gephyrin and Hsc70 double detection. C1, Hsc70-IR was detected in excitatory synapses (crossed arrow). C2, Presence of gold-labeled (2mRFP.Ge (arrow) in inhibitory PSD (double crossed arrow). Hsc70 was not detected. Scale bar, $100 \mathrm{~nm}$.

structures, respectively, it is unlikely that Hsc70 was bound to a misfolded G-domain. This was reinforced by the fact that other proteins of the Hsp70 family were not pulled down by any of the gephyrin baits. This further indicated that no abnormal confor- mation could favor binding of Hsp70s acting as molecular chaperones. Consistently, mass spectrometry revealed that among 13 peptides matching the Hsc70 sequence, 11 were found to belong specifically to Hsc70, the remaining two corresponding to shared primary structure in the $\mathrm{N}$-terminal region of the family members (supplemental Fig. 1, available at www.jneurosci.org as supplemental material). Therefore, Hsc70 is unambiguously a specific gephyrin molecular partner, which binds to its $\mathrm{N}$-terminal G-domain.

In our pull-down protocol, only soluble protein complexes or free proteins could provide ligands to the gephyrin preys. To confirm that the interaction between gephyrin and Hsc70 also occurred between endogenous molecules, a coimmunoprecipitation experiment was performed using mouse spinal cord extract (Fig. 1C). We used gephyrin-mRFP knock-in mice, which express a gephyrin that contains a T7tag and a monomeric red fluorescent protein (mRFP) sequence inserted into the $\mathrm{C} 2$ cassette of the gephyrin G-domain (supplemental Fig. 2, available at www.jneurosci. org as supplemental material). In this knock-in mouse, gephyrin splice variants modified by the insertion of a T7-mRFPtagged C2 cassette (C2mRFP.Ge) should be expressed endogenously in place of the wild-type protein. The $\mathrm{C} 2$ cassette is present in all known gephyrin variants detected at high level in neuronal and non-neuronal tissue (Rees et al., 2003; Paarmann et al., 2006), thus the distribution of the tags represents that of neuronal gephyrin molecules. We found that in these mice that C2mRFP.Ge was correctly and specifically clustered at inhibitory synapses (supplemental Figs. 4, 5, available at www.jneurosci.org as supplemental material) and interacted with its known partners GlyR and Pin1 (supplemental Fig. 3, available at www.jneurosci. org as supplemental material). Beads conjugated to anti-T7-tag antibody (Fig. 1C) immunoprecipitated endogenous gephyrin with a significant amount of Hsc70 and Pin1. When the anti-T7-beads were used with a spinal cord extract from wild-type mouse, these immunoreactivities were not recovered (Fig. 1C).

To further establish that Hsc70 and gephyrin could form complexes in a mammalian cell context, coimmunoprecipitation experiments from transiently transfected COS-7 cells expressing an mRFP-tagged version of full-length gephyrin [C2mRFP.Ge(2), Fig. $1 D$ ] were performed. Interaction of C2mRFP.Ge(2) with endogenous Hsc70 protein was obtained (Fig. 1E). In experiments with a control construct (T7-mRFP) lacking the gephyrin 
sequence from transfected COS-7 cells, Hsc70 was not coimmunoprecipitated, thus confirming the specificity of the interaction.

Altogether, these data demonstrate the existence of a physical interaction between gephyrin and $\mathrm{Hsc70}$ in mammalian cells.

Hsc70 is present at inhibitory synapses in spinal cord neurons $\mathrm{Hsc70}$ is enriched in the mammalian nervous system compared with non-neural tissues, and comprises $1-3 \%$ of total brain protein (Schlossman et al., 1984; Aquino et al., 1993). It is present at high levels in the somata of cortical, hippocampal and spinal cord neurons (Manzerra et al., 1993, 1997; Manzerra and Brown, 1996). Hsc70 is also detected in excitatory postsynaptic densities (PSDs) from synaptosomes and cultured hippocampal neurons (Walikonis et al., 2000; Moon et al., 2001; Li et al., 2004).

We analyzed the distribution of endogenous Hsc70 with regard to gephyrin-positive inhibitory synapses in spinal cord neurons, using homozygous gephyrin-mRFP knock-in mice (Fig. 2). In tissue sections, C2mRFP.Ge-associated fluorescence (supplemental Figs. 4, 5, available at www.jneurosci.org as supplemental material) were superimposed and predominantly observed as puncta apposed to VIAAT-positive termini in the hippocampus, the cerebellum and the spinal cord of the knock-in mouse. This fluorescence was found to colocalize with the $7 \mathrm{a}$ - and $2 \mathrm{~b}$ immunoreactivities for gephyrin and the glycine receptor, respectively (Sassoè-Pognetto et al., 1995; Vannier and Triller, 1997, see their references) (supplemental Figs. 5, 6, available at www.jneurosci.org as supplemental material). A quantitative analysis in spinal cord slices showed that colocalization of C2mRFP.Ge with gephyrin-IR ( $85.7 \pm 0.8 \%, n=25,3$ animals) and with VIAAT-IR (73.3 $\pm 1.2 \%, n=26,3$ animals) occurred with proportions identical to those found in wild-type animals (Dumoulin et al., 1999). In the ventral spinal cord, Hsc70 displayed a punctate distribution throughout neuronal somata and in neuropiles (data not shown). The localization of Hsc70 was examined by electron microscopy. In agreement with previous observations (Bodega et al., 2002), Hsc70-associated amplified nanogold particles were detected on the external surface of rough endoplasmic reticulum (Fig. 2A1) and the Golgi apparatus (Fig. $2 A 2$ ). It was also associated with microtubules in dendrites (Fig. 2A3). Hsc70-IR was detected at synapses which could be either symmetric with flat vesicles (Fig. 2A4,5) or asymmetric with round vesicles (Fig. 2A6), likely corresponding to inhibitory and excitatory connections (Peters and Palay, 1996). More precisely, $14 \%$ of all synapses $(n=99)$ were labeled and, among the inhibitory ones $(n=71), 17 \%$ contained Hsc70-IR.

At inhibitory synapses containing Hsc70-IR, gold-toned silver-intensified nanogold particles were detected $(44.0 \pm 0.3 \%$, $n=109$ ) in the vicinity of the PSD ( $\leq 100 \mathrm{~nm}$ from postsynaptic membrane, Fig. $2 A, B)$. They were observed on the cytoplasmic side of the plasma membrane or in association with adjacent cisternae (Fig. 2 A4,5, asterisk). These cisternae were comparable to those previously described (Gardiol et al., 1999) in the vicinity of spinal cord inhibitory synapses. Nanogold particles were present in inhibitory PSDs $(31.2 \pm 1.1 \%, n=109)$ and frequently at their edges (Fig. 2 B2,3). The inhibitory nature of labeled synapses was confirmed by the simultaneous detection of the gephyrin-associated T7 tag (Fig. 2B). Gephyrin-associated gold particles and $\mathrm{Hsc} 70$-associated silver-intensified nanogold particles colocalized as expected in the vicinity of inhibitory PSDs (Fig. $2 B 1,2$ ) or within the PSD (Fig. 2 B2,3). In these double labeling experiments, asymmetric synapses devoid of T7-gephyrinIR could exhibit Hsc70-IR (Fig. 2C1) and symmetric T7gephyrin-IR synapses could be Hsc70-IR-negative (Fig. 2C2).
A

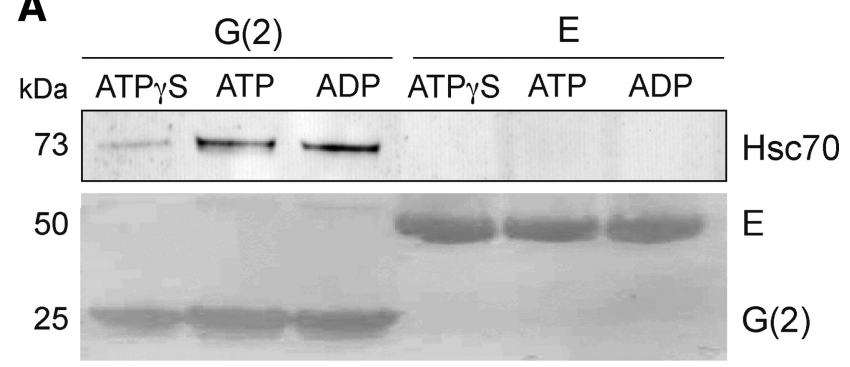

B

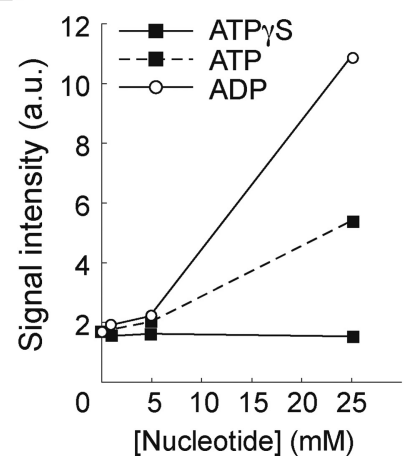

C

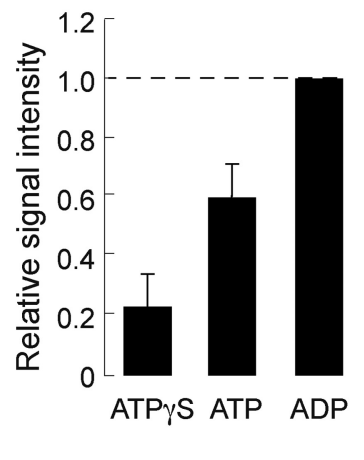

Figure 3. Hsc70 interacts directly with the G-domain of gephyrin in an ADP-dependent manner. $\boldsymbol{A}$, Purified recombinant $\mathrm{Hsc} 70$ was incubated with immobilized $\mathrm{G}(2)$ - or $\mathrm{E}$-domains of gephyrin in the presence of $5 \mathrm{~mm}$ ATP $\gamma \mathrm{S}, \mathrm{ATP}$ or ADP, as described in Materials and Methods. Bound $\mathrm{Hsc70}$ was detected after by Western blotting. Direct interaction of $\mathrm{Hsc70}$ was obtained only with the $\mathrm{G}$-domain ( $\mathrm{ECL}+$ detection, top). $\boldsymbol{B}$, Binding of $\mathrm{Hsc} 70$ recovered after capture by the $\mathrm{G}(2)$-domain in a similar experiment using nucleotide concentrations ranging from 0 to 25 $\mathrm{mm}$. No concentration-dependent effect of ATP $\gamma \varsigma$ was observed above the basal interaction of the two proteins obtained in the absence of nucleotide. $C$, Nucleotide effect ( 5 mm final concentration) normalized to that of ADP. Data were averaged from four independent experiments (mean \pm SEM). The presence of ATP resulted in a moderate increase in $\mathrm{Hsc70}$ binding to the G-domain.

This provided a good internal control of the absence of crossreactivity. A similar localization of $\mathrm{Hsc70}$ was also observed in wild-type mouse slices (supplemental Fig. 7, available at www. jneurosci.org as supplemental material).

\section{Gephyrin binding of Hsc70 is direct and ADP dependent}

Hsc70 has intrinsic ATPase activity (Chappell et al., 1986) and acts on its binding partners in an ATP-dependent manner. The affinity or dissociation rate of Hsc70 for its partner depends on its nucleotide-bound state in the ATP/ADP exchange cycle (Meimaridou et al., 2009, their references). This is so with the clathrin uncoating reaction (Schlossman et al., 1984), but clathrin binding/dissociation rates and disruption of clathrin-clathrin interactions have not been linked in detail to the ATPase reaction. To compare the stability/affinity of the complex formed between gephyrin and the various nucleotide-bound forms of $\mathrm{Hsc70}$, free or nucleotide preloaded recombinant $\mathrm{Hsc70}$ was pulled-down with either purified gephyrin G(2)- or E-domain in the presence of ATP, ATP $\gamma S$ (a non-hydrolyzed ATP analog), or ADP (Fig. 3). Hsc70 was pulled-down by G(2) protein, but not by the isolated E-domain (Fig. 3A), as expected from data reported above. Notably, the comparison of the binding over a $0-25 \mathrm{~mm}$ concentration range of nucleotide revealed that the capture of $\mathrm{Hsc} 70$ by the $\mathrm{G}(2)$-domain was the highest in the presence of ADP. The absence of effect of ATP $\gamma S$ at any concentration above the basal interaction (no nucleotide) indicates that ATP (before hydrolysis) poorly stabilized the binding of $\mathrm{Hsc70}$ to the gephyrin bait 

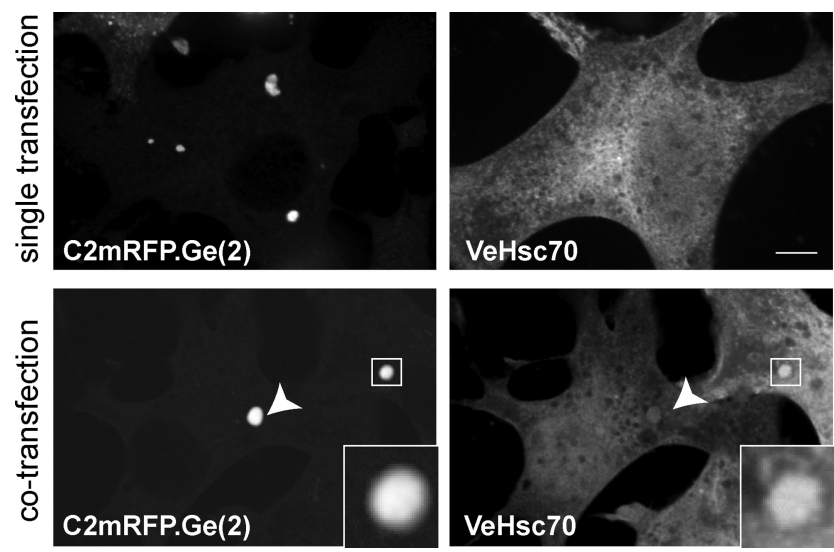

Figure 4. Hsc70 colocalizes with gephyrin in transfected $\operatorname{COS}-7$ cells. Fluorescence microscopy of COS-7 cells transfected with either (2mRFP.Ge(2) (top left) or VeHsc70 (top right) alone. Confocal images of COS-7 cells doubly transfected with C2mRFP.Ge(2) and VeHsc70 (bottom). Overexpressed recombinant gephyrin formed characteristic aggregates that recruit VeHsc70 (arrowhead, inset with magnification). Scale bar, $10 \mu \mathrm{m}$.

(Fig. 3B). Therefore, the observed ATP-dependent increase of the gephyrin-Hsc70 interaction likely resulted from the intrinsic ATPase activity of Hsc70. The reproducible intermediate recovery of the Hsc70 prey $(60 \pm 11 \%, n=4$; Fig. $3 C)$ suggests that ATP hydrolysis might be used to generate on $\mathrm{Hsc70}$ a gephyrinbinding site characterized by a low dissociation rate. This binding site was induced by the binding of ADP and did not occurred in the presence of ATP $\gamma \mathrm{S}(23 \pm 11 \%, n=4)$. These data demonstrate that the gephyrin-Hsc70 interaction is direct and indicate that, while occurring in the presence of any tested nucleotide, a gephyrin/Hsc70 complex stabilized by the ADP-bound form of Hsc70 can exist.

\section{Hsc70 colocalizes with gephyrin in transfected COS-7 cells}

In transfected non-neuronal cells, gephyrin forms large intracellular aggregates (Meyer et al., 1995) (Fig. 4), which have been reported to require the molecule's oligomerization (Saiyed et al., 2007). These gephyrin-rich cytoplasmic regions contain active gephyrin since it is able to recruit different partners, such as the GlyR $\beta$ peptide, collybistin or Dlc-2 (Kins et al., 1999, 2000; Fuhrmann et al., 2002). We therefore examined the subcellular distribution of gephyrin and Hsc70 localization upon coexpression in transfected COS-7 cells. When expressed alone, the recombinant C2mRFP.Ge(2) version of gephyrin spontaneously formed the known cytoplasmic aggregates (Fig. 4, top), whereas a Venus-tagged version of Hsc70 (VeHsc70) exhibited a diffuse cytoplasmic distribution (Fig. 4, top right). When coexpressed with gephyrin, VeHsc70 was partially recruited to gephyrin cytoplasmic aggregates (Fig. 4, bottom), indicating that gephyrin and Hsc70 interact in intact cells.

\section{Hsc70 colocalizes with gephyrin/GlyR complexes in transfected COS-7 cells}

The scaffold protein gephyrin directly interacts with the inhibitory neurotransmitter receptor GlyR via an 18-amino-acid sequence $(\beta \mathrm{gb})$ of the M3-M4 loop of its $\beta$-subunit (Meyer et al., 1995). As described previously in transfected cells (Meier et al., 2000a,b, 2001), the interaction of gephyrin with homo-oligomeric GlyR $\alpha 1 \beta \mathrm{gb}$ (a modified GlyR $\alpha 1$ subunit containing the gephyrinbinding sequence) changes the distribution pattern of both the receptor and the scaffold protein. In COS-7 cells, the large gephyrin intracellular aggregates formed in the absence of GlyR (Fig. 4, left images) are no longer observed in its presence. Instead, gephyrin partially translocates to the plasma membrane and forms coclusters with cell surface receptors. Colocalization of gephyrin and GlyR is not restricted to the plasma membrane, and also occurs within small aggregates inside the cell (Fig. 5), as previously reported (Meier et al., 2000a; Hanus et al., 2004).

To know whether Hsc70 distribution could also be modified in the presence of gephyrin/GlyR complexes, we cotransfected COS-7 cells with the mRFP-tagged gephyrin construct C2mRFP.Ge(2), the GlyR myc- $\alpha 1 \beta$ gb subunit and the Venustagged Hsc70 (VeHsc70). In these experiments we observed that VeHsc70 colocalized with C2mRFP.Ge(2) alone as well as associated with the myc- $\alpha 1 \beta \mathrm{gb}$ receptor (Fig. 5, top). In contrast, diffuse control EGFP failed to accumulate in GlyR-gephyrinpositive puncta (Fig. 5, bottom). This indicates that Hsc70 was able to participate in a ternary coaccumulation process with gephyrin and GlyR, and suggests that it can bind to submembrane gephyrin clusters in an intact non-neuronal cell system.

\section{Clustering of synaptic gephyrin involves Hsc70}

The interaction of Hsc70 with gephyrin together with its presence near and at inhibitory synapses suggested a role for the ATPase in the organization of the synaptic scaffold. To address this issue, we tested the effect of overexpressed Venus-tagged Hsc70 on the extent of gephyrin cluster formation, in transfected wild-type spinal cord neurons ( $8 \mathrm{DIV}$ ) in culture. After $2 \mathrm{~d}$, double staining for gephyrin and the surface GlyR $\alpha 1$-subunit was performed. Only coclusters of gephyrin and GlyR $\alpha 1$-immunoreactivities were quantified (Fig. 6). We found that overexpressed VeHsc70 significantly decreased the intensity of gephyrin clusters compared with control neurons transfected with EGFP (32 $\pm 5 \%$; EGFP, $n=60$ neurons; VeHsc70, $n=40$ neurons; 2 cultures; $p<$ $10^{-3}$, two-way ANOVA). Interestingly, GlyR-associated intensity was not modified within gephyrin/GlyR coclusters. Notably, no changes could be detected in the amount of the excitatory scaffold protein Homer at excitatory synapses (EGFP, $n=39$ neurons; VeHsc70, $n=43$ neurons; 2 cultures) (Fig. 6, bottom), reinforcing the notion that the activity of $\mathrm{Hsc70}$ at inhibitory synapses is selective.

To further confirm that $\mathrm{Hsc70}$ activity could regulate gephyrin polymerization, we analyzed the effect of Hsc70 inhibition. Cultured spinal cord neurons (10-12 DIV) were exposed to the drug CA, an Hsc70-specific competitive inhibitory ligand (Alvares et al., 1990; Huang et al., 1994). Hsc70 has a high affinity for CA and affinity chromatography studies using CA- or ATPmatrices have suggested that CA and ATP bind to the same or partially overlapping binding site(s) on Hsc70 (Alvares et al., 1990; Huang et al., 1994). It has been proposed that CA acts as a specific antagonist of the chaperone activity of $\mathrm{Hsc} 70$ in protein folding by disrupting its interaction with its substrate (Uma et al., 1999).

We determined the influence of CA on the Hsc70-gephyrin interaction. Purified Hsc70 protein was pulled-down with the purified G(2)-domain of gephyrin in the presence of ADP or CA (Fig. 7A). The amount of Hsc70 captured in the presence of CA was approximately twice $(230 \pm 32 \%, n=4)$ that with ADP, as quantified after Western blotting. Our interpretation is that, as proposed above for ADP, Hsc70 is strongly interacting with gephyrin when the acquisition of its ATP-dependent conformation is impaired. Thus, CA was used to inhibit Hsc70 ATPase activity and disrupt its potential function in gephyrin clustering in neurons. The rationale for this experiment was to lower the number of binding sites available for ATP on Hsc70 while favor- 

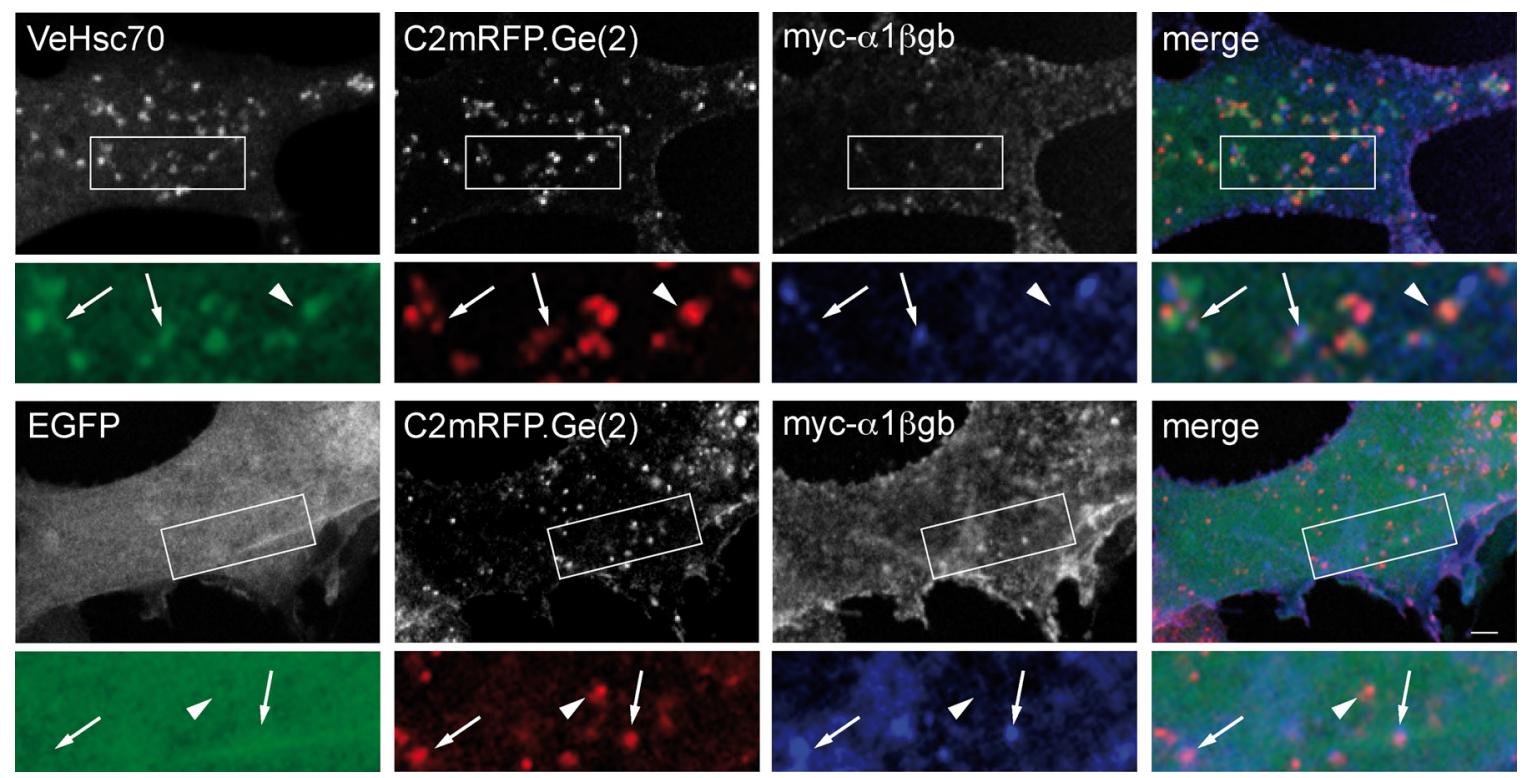

Figure 5. Recombinant Hsc70 colocalizes with intracellular gephyrin-GlyR complexes in COS-7 cells. Overexpression of VeHsc70 (top images) or EGFP (bottom images) with C2mRFP.Ge(2) and the GlyR myc- $\alpha 1 \beta \mathrm{gb}$ subunit. A higher magnification of the area delineated in the rectangle is shown. Note that VeHsc70 fluorescence colocalized with (2mRFP.Ge(2) associated (arrows) or not (arrowhead) with myc- $\alpha 1 \beta \mathrm{gb}$. In contrast, EGFP displayed no colocalization with C2mRFP.Ge(2) complexed (arrows) or not (arrowhead) with myc- $\alpha 1 \beta \mathrm{gb}$ subunit. Scale bar, $10 \mu \mathrm{m}$.
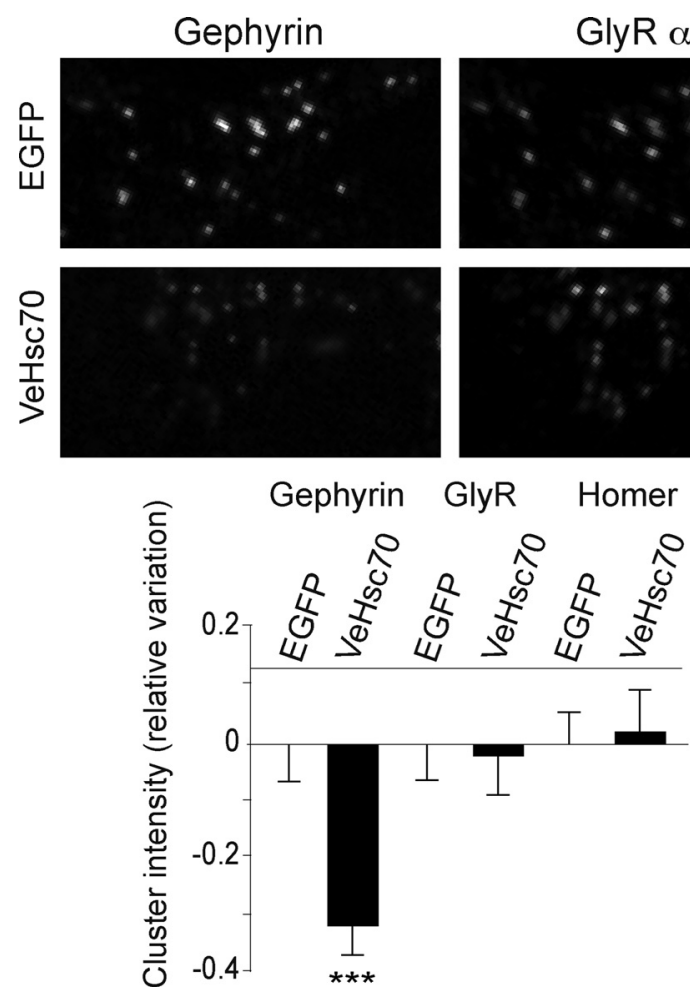

Figure 6. Overexpression of Hsc70 decreases gephyrin clustering at synapses. Wild-type spinal cord neurons were transfected at 8 DIV with Venus-tagged Hsc70 or with EGFP and fluorescence intensities (means \pm SEM) of gephyrin, GlyR, and Homer clusters after overexpression of Hsc70 were measured after $48 \mathrm{~h}$. Shown are variations of cluster integrated intensities normalized by the averaged integrated intensity obtained with EGFP overexpression. Note that the gephyrin-IRsignificantly decreased in neurons transfected with VeHsc70 (means \pm SEM, ${ }^{* * *} p<10^{-3}$, two-way ANOVA, two independentexperiments), while the GlyR $\alpha 1$ and Homer cluster intensities were unaffected. Scale bar, $5 \mu \mathrm{m}$.

ing the formation of gephyrin/Hsc70 complexes. In this experiment, gephyrin and surface GlyR clusters were analyzed after $48 \mathrm{~h}$ CA treatment on cultured spinal cord neurons derived from the homozygous gephyrin-mRFP knock-in mouse (Fig. $7 B, C$ ). The total fluorescence intensity of gephyrin and GlyR $\alpha 1$ coclusters were quantified. CA treatment increased the fluorescence intensity of gephyrin clusters by $27 \pm 5 \%$ compared with that measured in parallel control experiments (control, $n=123$ neurons; CA, $n=121$ neurons; 3 cultures; $p<10^{-3}$, two-way ANOVA). As in the case of Hsc70 overexpression experiments (see above), GlyR clusters remained unaffected by the CA treatment (Fig. 7B, bottom left). Thus CA strongly increased $(\sim 1.3$-fold $)$ the amount of clustered gephyrin without notable change in the amount of associated GlyR, as confirmed by the ratio of gephyrin to GlyR fluorescence quantification done cluster by cluster (control: $100 \pm 3 \%, n=4787$ clusters; CA: $131 \pm 6 \%, n=4682$ clusters; 3 cultures; $p<10^{-3}$, two-way ANOVA) (Fig. 7C, bottom right). This effect of $\mathrm{CA}$ was selective, the scaffold protein Homer in excitatory synapses was unchanged (control, $n=45$ neurons; CA, $n=45$ neurons; 2 cultures) (Fig. $6 B$, bottom left). Thus, Hsc70 regulation of gephyrin polymerization is independent of GlyR trapping.

\section{Clofibric acid induces a decrease of GlyR lateral diffusion}

The selective increase in the gephyrin synaptic accumulation not coupled to GlyR accumulation suggested that CA effects did not correspond to a mere differentiation-driven maturation of the synaptic GlyR/gephyrin complex (Dumoulin et al., 2000). To further characterize the impact of CA on GlyR-gephyrin interaction, we analyzed its lateral diffusion using single-particle tracking with quantum dots (QDs) as previously described (Dahan et al., 2003). Spinal cord neurons derived from homozygous gephyrin-mRFP knock-in mice were used at 10 DIV after $48 \mathrm{~h}$ treatment with CA (Fig. 8). Cell surface GlyR $\alpha 1$-subunit was labeled with QDs at low concentration to allow the detection and tracking of individual QDs. The lateral dynamics of GlyR inside and outside of gephyrin clusters was characterized by the mean square displacement (MSD) function. Portions of trajectories were defined as synaptic when they colocalized with C2mRFP.Ge clusters (Fig. 8A). QD-GlyRs exhibited a variety of motion, exchanging between extrasynaptic and synaptic areas and reducing their mobility when entering the gephyrin-enriched region (Fig. 
A

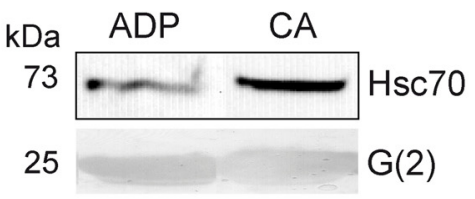

B
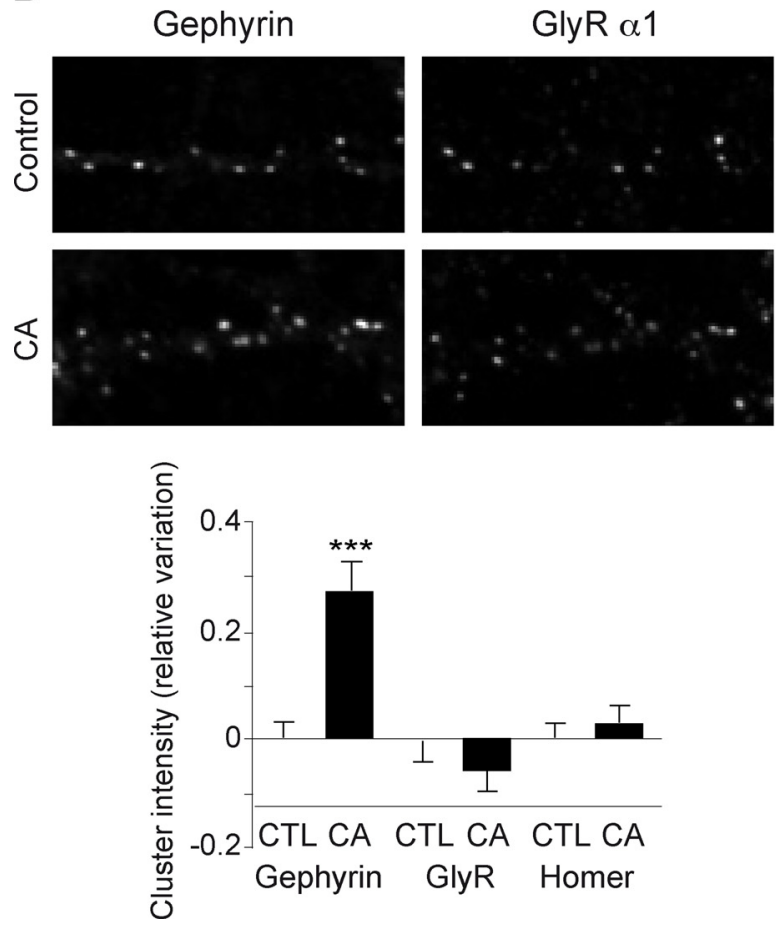

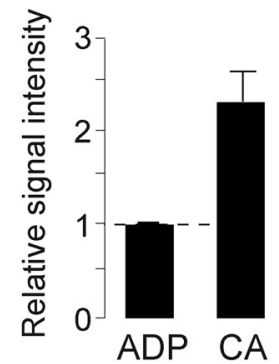

$\mathrm{C}$

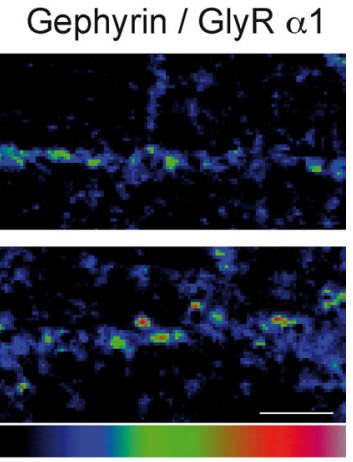

Figure 7. Hsc70 inhibition induces gephyrin clustering at synapses. A, CA caused an increase in gephyrin-Hsc70 interaction. The $\mathrm{G}(2)$-domain of gephyrin was incubated with purified $\mathrm{Hsc} 70$ in the presence of ADP or CA. Pulled-down Hsc70 was visualized after Western blotting (left). Band intensities were quantified and expressed relative to the signal intensity of the ADP treatment (means \pm SEM, four independent experiments) (right). The interaction of the G-domain of gephyrin with Hsc70 was potentiated in the presence of CA. B, C, Spinal cord neurons derived from homozygous gephyrin-mRFP knock-in mouse at 10 DIV were treated with $2 \mathrm{~mm}$ CA for $48 \mathrm{~h}$, and live-stained for the GlyR $\alpha 1$-subunit. Scale bar, $5 \mu \mathrm{m}$. $\boldsymbol{B}$, Normalized variation of integrated fluorescence intensities (means \pm SEM) of gephyrin, GlyR and Homer clusters (as shown on top) after CA treatment. Cluster measurements were normalized by the averaged cluster measurements obtained in control conditions. Note that the gephyrin cluster intensity significantly increased with CA ( ${ }^{* * *} p<10^{-3}$, two-way ANOVA, three independent experiments), while that of GlyR $\alpha 1$ and of Homer did not change (bottom). C, Ratio of gephyrin to GlyR $\alpha 1$ integrated fluorescence intensity done cluster by cluster was increased in the presence of CA (means \pm SEM, ${ }^{* * *} p<10^{-3}$, two-way ANOVA, three independent experiments).

$8 A 1,2)$. In agreement with previous reports (Meier et al., 2001; Dahan et al., 2003; Ehrensperger et al., 2007), QD-GlyRs displayed confined behavior when interacting with gephyrin clusters (Fig. 8A1), in contrast with their Brownian movement outside gephyrin clusters (Fig. 8A3). The diffusion coefficient $D$ of QDGlyRs colocalizing with gephyrin clusters was significantly reduced after $48 \mathrm{~h}$ of CA application (Fig. $7 \mathrm{~B}, C$; control: $D_{\text {median }}=9.710^{-3}$ $\mu \mathrm{m}^{2} \mathrm{~s}^{-1}, n=833$; CA: $D_{\text {median }}=5.310^{-3} \mu \mathrm{m}^{2} \mathrm{~s}^{-1}, n=737 ; 3$ cultures; $p<10^{-3}$, KS test). The CA-induced slowdown of GlyR diffusion was also observed outside gephyrin clusters (control, $n=$ 1444, CA, $n=1370$; 3 cultures; $p<10^{-3}$, KS test). Remarkably, diffusion was reduced for most of QD-GlyRs inside gephyrin clusters, whereas this was observed mainly for the slower subpopulation of receptors outside clusters (Fig. $8 \mathrm{~B}$ ). CA treatment did not modify the dwell time of GlyR inside the gephyrin compartment (Fig. 8D;

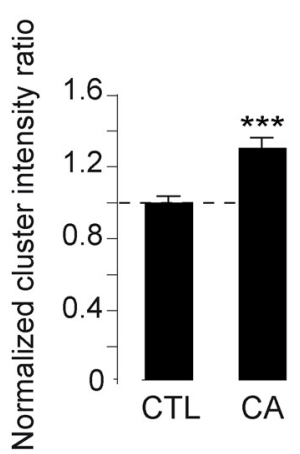

control: $11.23 \pm 0.30 \mathrm{~s} ; \mathrm{CA}: 11.18 \pm 0.35 \mathrm{~s})$. Together, our experiments showed that exposure of neurons to CA increased the number of gephyrin molecules in synaptic clusters without altering number of GlyRs. These data suggest that Hsc70 modulates the extent of gephyrin polymerization, and subsequently, the diffusion of gephyrinassociated GlyR independently of its trapping at synapses.

\section{Discussion}

The regulation of GlyR and $\mathrm{GABA}_{\mathrm{A}} \mathrm{R}$ number in the inhibitory postsynaptic differentiation relies on a set of proteins which form a subsynaptic scaffold. Several candidate proteins have recently been identified based on their possible interaction with gephyrin, though they are not systematically detected at inhibitory synapses (Fritschy et al., 2008). In the present study using a pull-down-based approach, we show that the ATPase Hsc70 is a gephyrin-binding protein. No other known mammalian chaperones (Hsp70, Hsp90) or cochaperone proteins (such as Hsp40, a cochaperone of Hsc70) intervening in protein folding were captured by gephyrin. Indeed, our experimental conditions did not favor the capture of proteins interacting with low affinity but reinforce the specificity for the recovered partners, explaining the fact that few proteins bound to gephyrin were identified by mass spectrometry. Moreover, in our assay gephyrin was expressed in bacteria and consequently adopt oligomerization properties that may differ from a native state in neuronal cells (Bedet et al., 2006; Saiyed et al., 2007), selecting pulled-down partners. Since gephyrin is a polyphosphorylated protein in a eukaryotic context, the lack of phosphorylation would prevent the binding to other partners such as Pin1 (Zita et al., 2007). We provide evidence that Hsc70 interaction with the G-domain of gephyrin is specific and direct, and that it is potentiated by ADP. Furthermore, this interaction exists in neuronal cells, as evidenced by the coimmunoprecipitation of complexed endogenous gephyrin and Hsc70 from a gephyrin-mRFP knock-in mouse spinal cord extracts. This was reinforced by immunoelectron microscopy showing the presence of Hsc70 in association with inhibitory PSDs. So far, the other molecular binding partners of gephyrin have been found to interact with either the unstructured central C-domain or the C-terminal E-domain of the protein (Fritschy et al., 2008). Our finding is the first evidence for the involvement of the $\mathrm{N}$-terminal structural domain of gephyrin in the binding to a molecular interactant.

Electron microscopy studies of spinal cord sections revealed Hsc70 at inhibitory synapses and its colocalization with gephyrin in the cytoplasm in the vicinity of the PSDs and in postsynaptic specializations, particularly at the edges of the differentiation. Hsc70 was also found at excitatory synapses, as described previ- 
ously (Suzuki et al., 1999; Bechtold et al., 2000; Walikonis et al., 2000; Moon et al., 2001). Interestingly, labeled subsynaptic cisternae in the vicinity of postsynaptic differentiations have been shown to include components of the protein synthesis machinery (Spacek and Harris, 1997; Gardiol et al., 1999), or to be subsynaptic endosomes (Kittler et al., 2001; Cooney et al., 2002). This favored the notion that these cisternae could be involved in local protein synthesis and trafficking. Moreover, Hsc70 colocalization with gephyrin-GlyR complexes in transfected COS-7 suggests that Hsc70 binds to membrane-associated gephyrin. Despite the possibility that the interactions of gephyrin and Hsc70 may occur at multiple sites, our ultrastructural data indicate that inhibitory PSDs are an important loci of $\mathrm{Hsc70}$ action.

Involvement of Hsc70 in gephyrin clustering in neurons was disclosed by transfection-induced overexpression and by inhibition using a specific antagonist, CA, which competitively inhibits both Hsc70 chaperone activity and interaction with substrate (Uma et al., 1999). However, CA potentiated Hsc70-gephyrin interaction in vitro, suggesting that gephyrin recognition relies on a conformation of Hsc70 distinct from that of its ATPbound form. This is at variance with the strong ATP-dependent interaction admitted for substrates of the Hsp70 family members (Erbse et al., 2004). Overexpression of Hsc70 led to a decrease of synaptic gephyrin in cultured neurons from gephyrin-mRFP knock-in mice. Consistently, CA increased the amount of gephyrin associated with the postsynaptic plasma membrane. These opposite effects on the synaptic clustering of gephyrin, which can thus be accounted for respectively by the increased or reduced ATPase activity of Hsc70, rely on the presence of the chaperone in the subsynaptic compartment. We hypothesize that Hsc70 activity controls the dynamics of the gephyrin lattice, in an ATP hydrolysis-manner. Thus, the modulation of gephyrin amount at synapses may result either from declustering or from a slowdown of clustering, two processes tuned by the local activity of Hsc70.

Real-time imaging revealed that GlyR diffuses randomly at the extrasynaptic membrane and is confined to synapses (Meier et al., 2001; Dahan et al., 2003; Ehrensperger et al., 2007). Moreover, extrasynaptic GlyR can diffuse in a gephyrin-bound state (Ehrensperger et al., 2007; Calamai et al., 2009) and alteration of gephyrin oligomerization modifies the lateral diffusion of GlyRgephyrin complexes (Calamai et al., 2009). The increase of gephyrin amount induced by $\mathrm{Hsc70}$ inhibition was paralleled by a decrease in lateral mobility of synaptic and extrasynaptic GlyR. Paradoxically, the increased gephyrin clustering did not lead to an increase in GlyR dwell time and in the corresponding immunoreactivity at synapses. Thus the addition of gephyrin molecules does not create additional binding sites for GlyR. On the other hand, the slowdown of the receptor diffusion indicates that there are more gephyrin molecules attached to diffusing receptors (Ehrensperger et al., 2007). This is compatible with the notion

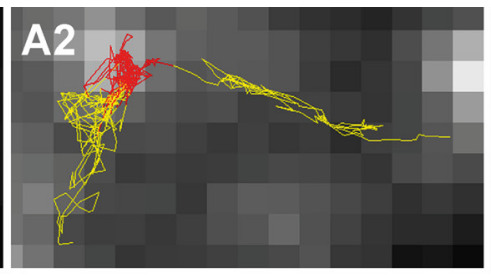

C

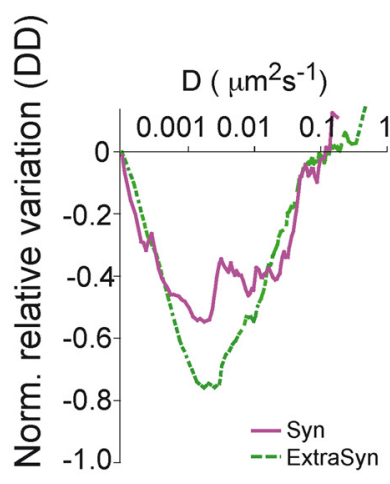

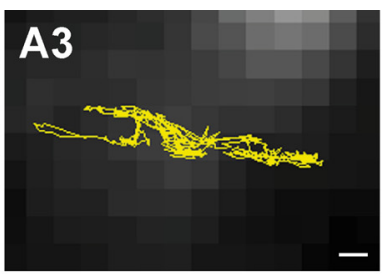

D

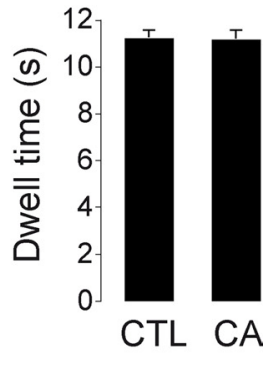

Figure 8. Hsc70 inhibition modifies membrane diffusion of GlyR but not the dwell time inside gephyrin clusters. Live imaging 列 efficient. $\Delta D$ was normalized to $D$ obtained under control conditions. Note the reduced diffusion rate of GlyR inside and outside gephyrin clusters in the presence of CA. D, Dwell time at synaptic loci throughout the 25 s recording session. Note that CA treatment induced no modification of synaptic dwell time of QD-GlyR (means \pm SEM). All data are from three independent cultures.

that not all gephyrin molecules represent synaptic receptor binding sites and, consequently, that GlyR trapping is not merely imposed by the local density of gephyrin molecules (Specht and Triller, 2008, see their references). This notion was already substantiated by our previous observation that excitatory activity can positively regulate GlyR accumulation at inhibitory synapses without increasing the number of gephyrin molecules in the PSDs (Lévi et al., 2008). This is similar to the situation seen at excitatory synapses where the number of scaffold molecules largely exceeds that of receptors (Chen et al., 2005; Sheng and Hoogenraad, 2007). Very likely gephyrin molecules are functionally heterogeneous within clusters with regard to GlyR binding. Altogether, our data suggest that Hsc70 activity decreases the amount of a gephyrin subpopulation not bound to GlyR. Actually, GlyR trapping at synapses require functional activation of gephyrin, an event relying on posttranslational modification(s) (Zita et al., 2007).

Hsc70 belongs to the family of ubiquitous $70 \mathrm{kDa}$ heat shock proteins (Hsp70s), long known for their participation in protein folding, but also for multiple cellular functions. In contrast with inducible cytosolic Hsp70s, Hsc enzymes are constitutively expressed (Rassow et al., 1995). As largely demonstrated for Hsc70 in the process of clathrin mantle dissociation from coated vesicles, they function in the ATP-dependent assembly/disassembly events for oligomeric protein complexes (Heuser and Steer, 1989; Gething and Sambrook, 1992; Ahn et al., 2005). A member of this Hsp70 family has been found to be associated with the acetylcholine receptor/rapsyn complex, raising the possibility that ATP hydrolysis is involved in the energetics of rapsyn accumulation 
and stabilization at the neuromuscular junction (Luo et al., 2008). Given that Hsp70 family members control the oligomerization of their substrate proteins (Bukau and Horwich, 1998) and that gephyrin polymerization must be regulated at synapses (Bedet et al., 2006), we propose that Hsc70 plays a key role at synapses and organizes gephyrin polymers. Whether the modulation of synaptic accumulation of gephyrin corresponds strictly to a control of polymerization/depolymerization event remains to be investigated.

Alternatively, ubiquitination can be promoted by $\mathrm{Hsc} 70$ (Meimaridou et al., 2009, see their references). The currently known roles for Hsc70 in intracellular trafficking, including endocytosis and exocytosis beside clathrin coat disassembly, are mediated by J cochaperones (Meimaridou et al., 2009, see their references). Cochaperones have also been implicated in the targeting to the ubiquitin proteasome system. The analysis of their function showed that they act by switching the Hsc70 chaperone machinery from a protein folding to a protein degradation role (Tateishi et al., 2004; Arndt et al., 2005). Therefore, the occurrence of a ubiquitination-promoting activity for Hsc70 may have significant influence on gephyrin amount and/or turnover in inhibitory synapses.

In conclusion, Hsc70 activity controls gephyrin declustering at synapses. This favors the notion that Hsc70 regulates the gephyrin assembly and disassembly steady-state equilibrium in an ATP hydrolysis-dependent process. This adds further to the modulation of the previously demonstrated oligomerization state of gephyrin by alternative splicing (Bedet et al., 2006). A key function of Hsc70 is that it limits the size of gephyrin clusters by counteracting its self-oligomerization. This is important since the gephyrin cluster size must be regulated to achieve a proper synaptic accumulation of GlyR (Lardi-Studler et al., 2007; Saiyed et al., 2007). It has been shown that an increase of excitatory spinal cord neuronal activity lead to an increase of inhibitory glycinergic transmission linked to an increase of receptor number at synapses (Lévi et al., 2008). However, this increased was not paralleled by that of gephyrin, thus indicating that newly bound receptors in the PSDs occupied free gephyrin binding sites. By controlling the amount of unbound gephyrin Hsc70 would prevent the activity-dependent tuning of GlyR number at inhibitory synapses.

\section{References}

Ahn SG, Kim SA, Yoon JH, Vacratsis P (2005) Heat-shock cognate 70 is required for the activation of heat-shock factor 1 in mammalian cells. Biochem J 392:145-152.

Alvares K, Carrillo A, Yuan PM, Kawano H, Morimoto RI, Reddy JK (1990) Identification of cytosolic peroxisome proliferator binding protein as a member of the heat shock protein HSP70 family. Proc Natl Acad Sci U S A 87:5293-5297.

Aquino DA, Klipfel AA, Brosnan CF, Norton WT (1993) The 70-kDa heat shock cognate protein (HSC70) is a major constituent of the CNS and is up-regulated only at the mRNA level in acute experimental autoimmune encephalomyelitis. J Neurochem 61:1340-1348.

Arndt V, Daniel C, Nastainczyk W, Alberti S, Höhfeld J (2005) BAG-2 acts as an inhibitor of the chaperone-associated ubiquitin ligase CHIP. Mol Biol Cell 16:5891-5900.

Bechtold DA, Rush SJ, Brown IR (2000) Localization of the heat-shock protein Hsp70 to the synapse following hyperthermic stress in the brain. J Neurochem 74:641-646.

Bedet C, Bruusgaard JC, Vergo S, Groth-Pedersen L, Eimer S, Triller A, Vannier C (2006) Regulation of gephyrin assembly and glycine receptor synaptic stability. J Biol Chem 281:30046-30056.

Blum H, Beier H, Gross HJ (1987) Improved silver staining of plant proteins, RNA and DNA in polyacrylamide gels. Electrophoresis 8:93-99.

Bodega G, Hernández C, Suárez I, Martín M, Fernández B (2002) HSP70 constitutive expression in rat central nervous system from postnatal development to maturity. J Histochem Cytochem 50:1161-1168.

Bukau B, Horwich AL (1998) The Hsp70 and Hsp60 chaperone machines. Cell 92:351-366.

Calamai M, Specht CG, Heller J, Alcor D, Machado P, Vannier C, Triller A (2009) Gephyrin oligomerization controls GlyR mobility and synaptic clustering. J Neurosci 29:7639-7648.

Campbell RE, Tour O, Palmer AE, Steinbach PA, Baird GS, Zacharias DA, Tsien RY (2002) A monomeric red fluorescent protein. Proc Natl Acad Sci U S A 99:7877-7882.

Cayatte C, Pons C, Guigonis JM, Pizzol J, Elies L, Kennel P, Rouquié D, Bars R, Rossi B, Samson M (2006) Protein profiling of rat ventral prostate following chronic finasteride administration: identification and localization of a novel putative androgen-regulated protein. Mol Cell Proteomics 5:2031-2043.

Chappell TG, Welch WJ, Schlossman DM, Palter KB, Schlesinger MJ, Rothman JE (1986) Uncoating ATPase is a member of the 70 kilodalton family of stress proteins. Cell 45:3-13.

Charrier C, Ehrensperger MV, Dahan M, Lévi S, Triller A (2006) Cytoskeleton regulation of glycine receptor number at synapses and diffusion in the plasma membrane. J Neurosci 26:8502-8511.

Chen X, Vinade L, Leapman RD, Petersen JD, Nakagawa T, Phillips TM, Sheng M, Reese TS (2005) Mass of the postsynaptic density and enumeration of three key molecules. Proc Natl Acad Sci U S A 102:11551-11556.

Cooney JR, Hurlburt JL, Selig DK, Harris KM, Fiala JC (2002) Endosomal compartments serve multiple hippocampal dendritic spines from a widespread rather than a local store of recycling membrane. J Neurosci 22:2215-2224.

Dahan M, Lévi S, Luccardini C, Rostaing P, Riveau B, Triller A (2003) Diffusion dynamics of glycine receptors revealed by single-quantum dot tracking. Science 302:442-445.

Dumoulin A, Rostaing P, Bedet C, Lévi S, Isambert MF, Henry JP, Triller A, Gasnier B (1999) Presence of the vesicular inhibitory amino acid transporter in GABAergic and glycinergic synaptic terminal boutons. J Cell Sci 112:811-823.

Dumoulin A, Lévi S, Riveau B, Gasnier B, Triller A (2000) Formation of mixed glycine and GABAergic synapses in cultured spinal cord neurons. Eur J Neurosci 12:3883-3892.

Ehrensperger MV, Hanus C, Vannier C, Triller A, Dahan M (2007) Multiple association states between glycine receptors and gephyrin identified by SPT analysis. Biophys J 92:3706-3718.

Erbse A, Mayer MP, Bukau B (2004) Mechanism of substrate recognition by Hsp70 chaperones. Biochem Soc Trans 32:617-621.

Fritschy JM, Harvey RJ, Schwarz G (2008) Gephyrin: where do we stand, where do we go? Trends Neurosci 31:257-264.

Fuhrmann JC, Kins S, Rostaing P, El Far O, Kirsch J, Sheng M, Triller A, Betz H, Kneussel M (2002) Gephyrin interacts with Dynein light chains 1 and 2, components of motor protein complexes. J Neurosci 22:5393-5402.

Gardiol A, Racca C, Triller A (1999) Dendritic and postsynaptic protein synthetic machinery. J Neurosci 19:168-179.

Gething MJ, Sambrook J (1992) Protein folding in the cell. Nature 355:33-45.

Giesemann T, Schwarz G, Nawrotzki R, Berhörster K, Rothkegel M, Schlüter K, Schrader N, Schindelin H, Mendel RR, Kirsch J, Jockusch BM (2003) Complex formation between the postsynaptic scaffolding protein gephyrin, profilin, and Mena: a possible link to the microfilament system. J Neurosci 23:8330-8339.

Hanus C, Vannier C, Triller A (2004) Intracellular association of glycine receptor with gephyrin increases its plasma membrane accumulation rate. J Neurosci 24:1119-1128.

Hanus C, Ehrensperger MV, Triller A (2006) Activity-dependent movements of postsynaptic scaffolds at inhibitory synapses. J Neurosci 26:4586-4595

Heuser J, Steer CJ (1989) Trimeric binding of the 70-kD uncoating ATPase to the vertices of clathrin triskelia: a candidate intermediate in the vesicle uncoating reaction. J Cell Biol 109:1457-1466.

Huang Q, Alvares K, Chu R, Bradfield CA, Reddy JK (1994) Association of peroxisome proliferator-activated receptor and Hsp72. J Biol Chem 269:8493-8497.

Kim EY, Schrader N, Smolinsky B, Bedet C, Vannier C, Schwarz G, Schindelin $H$ (2006) Deciphering the structural framework of glycine receptor anchoring by gephyrin. EMBO J 25:1385-1395.

Kins S, Kuhse J, Laube B, Betz H, Kirsch J (1999) Incorporation of a 
gephyrin-binding motif targets NMDA receptors to gephyrin-rich domains in HEK 293 cells. Eur J Neurosci 11:740-744.

Kins S, Betz H, Kirsch J (2000) Collybistin, a newly identified brain-specific GEF, induces submembrane clustering of gephyrin. Nat Neurosci 3:22-29.

Kirsch J, Langosch D, Prior P, Littauer UZ, Schmitt B, Betz H (1991) The 93-kDa glycine receptor-associated protein binds to tubulin. J Biol Chem 266:22242-22245.

Kittler JT, Rostaing P, Schiavo G, Fritschy JM, Olsen R, Triller A, Moss SJ (2001) The subcellular distribution of GABARAP and its ability to interact with NSF suggest a role for this protein in the intracellular transport of GABA(A) receptors. Mol Cell Neurosci 18:13-25.

Lardi-Studler B, Smolinsky B, Petitjean CM, Koenig F, Sidler C, Meier JC, Fritschy JM, Schwarz G (2007) Vertebrate-specific sequences in the gephyrin E-domain regulate cytosolic aggregation and postsynaptic clustering. J Cell Sci 120:1371-1382.

Lavoie SB, Albert AL, Handa H, Vincent M, Bensaude O (2001) The peptidyl-prolyl isomerase Pin 1 interacts with hSpt5 phosphorylated by Cdk9. J Mol Biol 312:675-685.

Lévi S, Schweizer C, Bannai H, Pascual O, Charrier C, Triller A (2008) Homeostatic regulation of synaptic GlyR numbers driven by lateral diffusion. Neuron 59:261-273.

Li KW, Hornshaw MP, Van Der Schors RC, Watson R, Tate S, Casetta B, Jimenez CR, Gouwenberg Y, Gundelfinger ED, Smalla KH, Smit AB (2004) Proteomics analysis of rat brain postsynaptic density. Implications of the diverse protein functional groups for the integration of synaptic physiology. J Biol Chem 279:987-1002.

Liu MT, Wuebbens MM, Rajagopalan KV, Schindelin H (2000) Crystal structure of the gephyrin-related molybdenum cofactor biosynthesis protein MogA from Escherichia coli. J Biol Chem 275:1814-1822.

Luo S, Zhang B, Dong XP, Tao Y, Ting A, Zhou Z, Meixiong J, Luo J, Chiu FC, Xiong WC, Mei L (2008) HSP90 beta regulates rapsyn turnover and subsequent $A C h R$ cluster formation and maintenance. Neuron 60:97-110.

Maas C, Belgardt D, Lee HK, Heisler FF, Lappe-Siefke C, Magiera MM, van Dijk J, Hausrat TJ, Janke C, Kneussel M (2009) Synaptic activation modifies microtubules underlying transport of postsynaptic cargo. Proc Natl Acad Sci U S A 106:8731-8736.

Mammoto A, Sasaki T, Asakura T, Hotta I, Imamura H, Takahashi K, Matsuura Y, Shirao T, Takai Y (1998) Interactions of drebrin and gephyrin with profilin. Biochem Biophys Res Commun 243:86-89.

Manzerra P, Brown IR (1996) The neuronal stress response: nuclear translocation of heat shock proteins as an indicator of hyperthermic stress. Exp Cell Res 229:35-47.

Manzerra P, Rush SJ, Brown IR (1993) Temporal and spatial distribution of heat shock mRNA and protein (hsp70) in the rabbit cerebellum in response to hyperthermia. J Neurosci Res 36:480-490.

Manzerra P, Rush SJ, Brown IR (1997) Tissue-specific differences in heat shock protein hsc70 and hsp70 in the control and hyperthermic rabbit. J Cell Physiol 170:130-137.

Meier J, De Chaldée M, Triller A, Vannier C (2000a) Functional heterogeneity of gephyrins. Mol Cell Neurosci 16:566-577.

Meier J, Meunier-Durmort C, Forest C, Triller A, Vannier C (2000b) Formation of glycine receptor clusters and their accumulation at synapses. J Cell Sci 113:2783-2795.

Meier J, Vannier C, Sergé A, Triller A, Choquet D (2001) Fast and reversible trapping of surface glycine receptors by gephyrin. Nat Neurosci 4:253-260.

Meimaridou E, Gooljar SB, Chapple JP (2009) From hatching to dispatching: the multiple cellular roles of the Hsp70 molecular chaperone machinery. J Mol Endocrinol 42:1-9.

Meyer G, Kirsch J, Betz H, Langosch D (1995) Identification of a gephyrin binding motif on the glycine receptor beta subunit. Neuron 15:563-572.

Moon IS, Park IS, Schenker LT, Kennedy MB, Moon JI, Jin I (2001) Presence of both constitutive and inducible forms of heat shock protein 70 in the cerebral cortex and hippocampal synapses. Cereb Cortex 11:238-248.

Nagai T, Ibata K, Park ES, Kubota M, Mikoshiba K, Miyawaki A (2002) A variant of yellow fluorescent protein with fast and efficient maturation for cell-biological applications. Nat Biotechnol 20:87-90.

Paarmann I, Schmitt B, Meyer B, Karas M, Betz H (2006) Mass spectrometric analysis of glycine receptor-associated gephyrin splice variants. J Biol Chem 281:34918-34925.

Peters A, Palay SL (1996) The morphology of synapses. J Neurocytol 25:687-700.
Prior P, Schmitt B, Grenningloh G, Pribilla I, Multhaup G, Beyreuther K, Maulet Y, Werner P, Langosch D, Kirsch J (1992) Primary structure and alternative splice variants of gephyrin, a putative glycine receptor-tubulin linker protein. Neuron 8:1161-1170.

Racine V, Sachse M, Salamero J, Fraisier V, Trubuil A, Sibarita JB (2007) Visualization and quantification of vesicle trafficking on a threedimensional cytoskeleton network in living cells. J Microsc 225:214-228.

Rassow J, Voos W, Pfanner N (1995) Partner proteins determine multiple functions of Hsp70. Trends Cell Biol 5:207-212.

Rees MI, Harvey K, Ward H, White JH, Evans L, Duguid IC, Hsu CC, Coleman SL, Miller J, Baer K, Waldvogel HJ, Gibbon F, Smart TG, Owen MJ, Harvey RJ, Snell RG (2003) Isoform heterogeneity of the human gephyrin gene (GPHN), binding domains to the glycine receptor, and mutation analysis in hyperekplexia. J Biol Chem 278:24688-24696.

Rosenberg M, Meier J, Triller A, Vannier C (2001) Dynamics of glycine receptor insertion in the neuronal plasma membrane. J Neurosci 21:5036-5044

Sabatini DM, Barrow RK, Blackshaw S, Burnett PE, Lai MM, Field ME, Bahr BA, Kirsch J, Betz H, Snyder SH (1999) Interaction of RAFT1 with gephyrin required for rapamycin-sensitive signaling. Science 284:1161-1164.

Saiyed T, Paarmann I, Schmitt B, Haeger S, Sola M, Schmalzing G, Weissenhorn W, Betz H (2007) Molecular basis of gephyrin clustering at inhibitory synapses: role of G- and E-domain interactions. J Biol Chem 282:5625-5632.

Sassoè-Pognetto M, Kirsch J, Grünert U, Greferath U, Fritschy JM, Möhler H, Betz H, Wässle H (1995) Colocalization of gephyrin and GABAAreceptor subunits in the rat retina. J Comp Neurol 357:1-14.

Schägger H, von Jagow G (1987) Tricine-sodium dodecyl sulfatepolyacrylamide gel electrophoresis for the separation of proteins in the range from 1-100 kDa. Anal Biochem 166:368-379.

Schlossman DM, Schmid SL, Braell WA, Rothman JE (1984) An enzyme that removes clathrin coats: purification of an uncoating ATPase. J Cell Biol 99:723-733.

Schrader N, Kim EY, Winking J, Paulukat J, Schindelin H, Schwarz G (2004) Biochemical characterization of the high affinity binding between the glycine receptor and gephyrin. J Biol Chem 279:18733-18741.

Sheng M, Hoogenraad CC (2007) The postsynaptic architecture of excitatory synapses: a more quantitative view. Annu Rev Biochem 76:823-847.

Sola M, Bavro VN, Timmins J, Franz T, Ricard-Blum S, Schoehn G, Ruigrok RW, Paarmann I, Saiyed T, O'Sullivan GA, Schmitt B, Betz H, Weissenhorn W (2004) Structural basis of dynamic glycine receptor clustering by gephyrin. EMBO J 23:2510-2519.

Spacek J, Harris KM (1997) Three-dimensional organization of smooth endoplasmic reticulum in hippocampal CA1 dendrites and dendritic spines of the immature and mature rat. J Neurosci 17:190-203.

Specht CG, Triller A (2008) The dynamics of synaptic scaffolds. Bioessays 30:1062-1074.

Suzuki T, Usuda N, Murata S, Nakazawa A, Ohtsuka K, Takagi H (1999) Presence of molecular chaperones, heat shock cognate (Hsc) 70 and heat shock proteins (Hsp) 40, in the postsynaptic structures of rat brain. Brain Res 816:99-110.

Tateishi Y, Kawabe Y, Chiba T, Murata S, Ichikawa K, Murayama A, Tanaka K, Baba T, Kato S, Yanagisawa J (2004) Ligand-dependent switching of ubiquitin-proteasome pathways for estrogen receptor. EMBO J 23: 4813-4823.

Triller A, Choquet D (2008) New concepts in synaptic biology derived from single-molecule imaging. Neuron 59:359-374.

Uma S, Thulasiraman V, Matts RL (1999) Dual role for Hsc70 in the biogenesis and regulation of the heme-regulated kinase of the alpha subunit of eukaryotic translation initiation factor 2. Mol Cell Biol 19:5861-5871.

Vannier C, Triller A (1997) Biology of the postsynaptic glycine receptor. Int Rev Cytol 176:201-244.

Walikonis RS, Jensen ON, Mann M, Provance DW Jr, Mercer JA, Kennedy MB (2000) Identification of proteins in the postsynaptic density fraction by mass spectrometry. J Neurosci 20:4069-4080.

Xiang S, Nichols J, Rajagopalan KV, Schindelin H (2001) The crystal structure of Escherichia coli MoeA and its relationship to the multifunctional protein gephyrin. Structure 9:299-310.

Zita MM, Marchionni I, Bottos E, Righi M, Del Sal G, Cherubini E, Zacchi P (2007) Postphosphorylation prolyl isomerization of gephyrin represents a mechanism to modulate glycine receptors function. EMBO J 26:1761-1771. 